\title{
Novel genes required for surface-associated motility in
}

\section{Acinetobacter baumannii}

3

4

Ulrike Blaschke $^{a, b, *}$, Evelyn Skiebe ${ }^{a}$ and Gottfried Wilharm ${ }^{a, c, *}$

a Robert Koch-Institute, Project group P2, Burgstr. 37, D-38855 Wernigerode,

* Corresponding addresses: ulrikeblaschke@googlemail.com; WilharmG@rki.de

${ }^{b}$ ORCID: 0000-0002-3496-5447

11

${ }^{c}$ ORCID: 0000-0002-1771-6799

\section{Keywords}

Acinetobacter baumannii, surface-associated motility, transposon mutant library, pellicle biofilm, antibiotic resistance, Galleria mellonella

\section{Funding}

19 This project was funded by the Deutsche Forschungsgemeinschaft (DFG) within FOR 2251 (WI 3272/3-1 and WI 3272/3-2). 


\section{Abstract}

Acinetobacter baumannii is an opportunistic and increasingly multi-drug resistant human pathogen rated as a critical priority 1 pathogen for the development of new antibiotics by the WHO in 2017. Despite the lack of flagella, A. baumannii can move along wet surfaces in 2 different ways: via twitching motility and surface-associated motility. While twitching motility is known to depend on type IV pili, the mechanism of surface-associated motility is poorly understood. In this study we established a library of 30 A. baumannii ATCC 17978 mutants that displayed deficiency in surfaceassociated motility. By making use of natural competence we also introduced these mutations into strain 29D2 to differentiate strain-specific versus species-specific effects of mutations. Mutated genes were associated with purine/pyrimidine/folate biosynthesis (e.g. purH, purF, purM, purE), alarmone/stress metabolism (e.g. Ap4A hydrolase), RNA modification/regulation (e.g. methionyl-tRNA synthetase), outer membrane proteins (e.g. ompA), and genes involved in natural competence (comEC). All tested mutants originally identified as motility-deficient in strain ATCC 17978 also displayed a motility-deficient phenotype in 29D2. By contrast, further comparative characterization of the mutant sets of both strains regarding pellicle biofilm formation, antibiotic resistance, and virulence in the Galleria mellonella infection model revealed numerous strain-specific mutant phenotypes. Our studies highlight the need for comparative analyses to characterize gene functions in A. baumannii and for further studies on the mechanisms underlying surfaceassociated motility. 


\section{Introduction}

Acinetobacter baumannii is a Gram-negative and strictly aerobic coccobacillus [1,2]. Being an opportunistic human pathogen [3], A. baumannii is associated with nosocomial diseases including soft tissue, bloodstream, and urinary tract infections as well as pneumonia [2]. Worldwide, about $9 \%$ of culture-positive infections found in intensive care units arise from Acinetobacter spp. [4]. Increased multi-drug resistance in $A$. baumannii has become problematic in recent years [5,6]. A global surveillance study found that $44 \%$ of 18,741 collected isolates were multi-drug resistant. During the study period the proportion of multi-drug resistant $A$. baumannii isolates increased from $23 \%$ in 2004 to $63 \%$ in 2014 [7]. As a consequence of rising multidrug resistance, $A$. baumannii was rated as one of the critical priority 1 pathogens for the development of new antibiotics by the WHO in 2017 [8]. Drug resistance and environmental persistence have enabled $A$. baumannii to successfully establish in the hospital environment. Some clinical isolates can survive 100 days or more under dry conditions [9-13]. An important factor for the interaction of $A$. baumannii with biotic or abiotic surfaces is the formation of biofilms, a feature that is associated with an increased tolerance to desiccation stress [14].

A connection between $A$. baumannii virulence and motility has been shown in the Caenorhabditis elegans infection model where hypermotility resulted in increased virulence [15]. Although A. baumannii does not produce flagella, it is capable of moving in two different ways: via twitching motility and surface-associated motility. For A. baumannii, twitching motility has been shown to depend on type IV pili (T4P) $[16,17]$ which drive the bacteria via retraction of attached T4P [18-25]. Inactivation of the putative T4P retraction ATPase pilT reduces twitching motility $[26-28,11]$ but does not abolish surface-associated motility $[26,16]$. Surface-associated motility in $A$. 
baumannii occurs at the surface of semi-dry media and is independent of T4P $[26,29]$. Surface-associated motility is poorly understood mechanistically, but was demonstrated to be controlled by quorum sensing [26], light [30], and iron availability $[31,32]$. Also, the synthesis of 1,3-diaminopropane (DAP) [33] and lipopolysaccharide (LPS) production [32] were shown to contribute to surface-associated motility of $A$. baumannii. Several genes have been identified which contribute to $A$. baumannii's capacity for surface-associated motility [26,32], including a ribonuclease T2 family protein [34] and the superoxide dismutase SodB [35]. A recent study revealed the regulatory control of surface-associated motility and biofilm formation by a cyclic-diGMP signaling network in A. baumannii strain ATCC 17978 [36]. Interestingly, studies on phase-variable phenotypes in A. baumannii strain AB5075 showed that "opaque phase" bacterial colonies had improved surface-associated motility $[37,38]$. A correlation between pellicle biofilm formation and surface-associated motility has been described in A. baumannii [39]. Given the fact that many A. baumannii clinical isolates exhibit surface-associated motility, it could be an important trait associated with infection $[33,28,26]$.

To investigate the mechanisms underlying surface-associated motility, we utilized a previously generated transposon mutant library of ATCC 17978 [33] which we screened for a surface-associated motility-deficient phenotype. The motility-deficient mutations were found to affect purine/pyrimidine/folate biosynthesis, alarmone/stress metabolism, RNA modification/regulation, outer membrane proteins, and DNA modification. We characterized these mutants with respect to growth, pellicle biofilm formation, antibiotic resistance, and virulence in the Galleria mellonella infection model. To facilitate distinguishing between strain-specific and species-specific traits 
some mutations were also introduced into the naturally competent $A$. baumannii strain 29D2 [40].

\section{Materials and Methods}

\section{Bacterial strains and culture conditions}

A. baumannii strain ATCC 17978 was purchased from LGC Promochem. The A. baumannii strain 29D2 was isolated from a white stork [40] and is naturally competent [41]. All strains were grown at $37^{\circ} \mathrm{C}$ in Luria-Bertani (LB) broth or on LB agar, and mutants were supplemented with $50 \mu \mathrm{g} / \mathrm{mL}$ of kanamycin. All strains used in this work are listed in supplementary Table S1. Single colonies were used as inoculum for overnight cultures or motility plates. Neither strain ATCC 17978 nor strain 29D2 exhibited phase variation $[38,37,42]$.

\section{Bacterial transformation and generation of an A. baumannii mutant library}

ATCC 17978 transposon mutants were generated using the EZ-Tn5 ${ }^{\mathrm{TM}}<\mathrm{KAN}-2>$ Insertion Kit (Epicentre Biotechnologies) as previously described [33]. Transformation of the transposome complex into ATCC 17978 was performed by electroporation [43]. 29D2 mutants were generated by making use of the strain's ability for natural competence. The transforming DNA was isolated from the ATCC 17978 mutants described above. A suspension of DNA-accepting bacteria was generated by resuspending a few colonies in $100 \mu \mathrm{L}$ of sterile PBS. The bacterial suspension was then mixed with equal volumes of the transforming DNA $(\sim 400 \mathrm{ng} / \mu \mathrm{L})$. This mixture was stabbed into motility agar plates 10 times, pipetting $2 \mu \mathrm{L}$ of the mixture with each 
stabbing [16]. The motility plates were incubated for $18 \mathrm{~h}$ at $37^{\circ} \mathrm{C}$. After incubation, the bacteria were flushed off the motility plates with $1 \mathrm{~mL}$ of sterile PBS and $100 \mu \mathrm{L}$ was plated on selective agar plates (50 g/mL of kanamycin). After sub-culturing of selected colonies transformation was confirmed by PCR.

\section{Identification of transposon insertion sites by single-primer PCR}

To identify the transposon insertion sites of ATCC 17978 motility mutants, singleprimer PCR was performed as described previously [33] using one of the following primers: FP-2Kana 5'-CTTCCCGACAACGCAGACCG-3'; FP-3Kana 5'-

GAGTTGAAGGATCAGATCACGC-3';

RP-2Kana

5'-

CCCTTGTATTACTGTTTATGTAAGC-3';

RP-3Kana

5'-

CGCGGCCTCGAGCAAGACG-3';

Tn5-Kana-For4

5'-

GTTTTCTCCTTCATTACAGAAACG-3';

and

Tn5-Kana-Rev4

5'-

CCCATACAATCGATAGATTGTCG-3'. Transposon insertions of all mutants (ATCC 17978 and 29D2) were confirmed by PCR using primers for the EZ-Tn5 ${ }^{\mathrm{TM}}<\mathrm{KAN}-2>$ kanamycin cassette (Suppl. Fig. S1), which are specified in the manufacturer's instructions, and appropriate gene target site primers (Suppl. Table S2; Suppl. Figs. S2 and S3).

\section{Surface-associated motility}

Motility assays were performed as described previously [33]. A single bacterial colony from a nutrient agar plate (Oxoid) or selective agar plates (supplemented with 50 $\mu \mathrm{g} / \mathrm{mL}$ of kanamycin for the mutants) of either wildtype (ATCC 17978 and 29D2) or mutants was lifted with a pipette tip and transferred to the surface of a motility plate 
$139(0.5 \%$ agarose $)$. Plates were incubated for $16 \mathrm{~h}$ at $37^{\circ} \mathrm{C}$. The diameter of the surface 140 motility spreading zone was measured and quadruplicates were statistically 141 analyzed.

\section{Bacterial growth curves}

Growth curves were determined by growing overnight cultures at $37^{\circ} \mathrm{C}$ in LB medium (supplemented with $50 \mu \mathrm{g} / \mathrm{mL}$ of kanamycin for the mutants). Overnight cultures were adjusted to $1 \mathrm{OD}(600 \mathrm{~nm})$ in LB medium. In $250 \mathrm{~mL}$ baffled flasks, $50 \mathrm{~mL}$ of LB medium (without antibiotics) was inoculated with $1 \mathrm{~mL}$ of the OD-adjusted inoculum. The cultures were incubated at $37^{\circ} \mathrm{C}$ for $9 \mathrm{~h}$ with shaking at $160 \mathrm{rpm}$. OD measurements at $600 \mathrm{~nm}$ were performed every hour by sampling $100 \mu \mathrm{L}$ of every culture. For each strain, data obtained from 3 independent cultures grown on the same day were averaged and represented by the mean \pm SD.

\section{Infection in the Galleria mellonella caterpillar}

For G. mellonella caterpillar infection, bacteria were grown in LB medium overnight at

$5 \mathrm{~min}$ at $7500 \mathrm{rpm}$ at room temperature (RT) and the supernatant was discarded.

Bacteria were resuspended in $500 \mu \mathrm{L}$ sterile PBS, adjusted to an $\mathrm{OD}_{600} \mathrm{~nm}$ of 1.0

161 caterpillars (purchased from TZ-TERRARISTIK, Germany, and BioSystems

162 Technology TruLarv, UK). As a control, caterpillars were injected with $5 \mu \mathrm{L}$ of sterile 
PBS. Three independent experiments were performed with groups of 16 caterpillars for every bacterial strain and control. The caterpillars were incubated at $37^{\circ} \mathrm{C}$ for 5 days and checked daily for vitality. Experiments with more than 2 dead caterpillars by serial dilutions, plated on nutrient agar, and colonies were counted after incubation at $37^{\circ} \mathrm{C}$ for $18 \mathrm{~h}$. For each strain, data obtained from 3 independent experiments were averaged and represented by the mean \pm SD.

\section{Determination of susceptibility to antibiotics}

172

For the minimal inhibitory concentration (MIC) tests, bacteria were grown in LB medium overnight at $37^{\circ} \mathrm{C}$ (to mutant strains $50 \mu \mathrm{g} / \mathrm{mL}$ of kanamycin was added). Cultures were diluted 1:50 in LB medium and incubated (without antibiotics) another $4 \mathrm{~h}$ at $37^{\circ} \mathrm{C}$. Agar plates were flushed with $2 \mathrm{~mL}$ of each culture and E-test strips (Liofilchem, Italy) were deposited on nutrient agar plates. MICs were determined after incubation for $16 \mathrm{~h}$ at $37^{\circ} \mathrm{C}$. Three independent experiments were performed and statistical significance was tested by the Student's $t$ test (2-tailed, unpaired).

\section{Pellicle biofilm assays}

A. baumannii strains were grown in LB medium overnight at $37^{\circ} \mathrm{C}(50 \mu \mathrm{g} / \mathrm{mL}$ of kanamycin was added to mutant strains). The cultures were adjusted to an $\mathrm{OD}_{600} \mathrm{~nm}$ of 1.0 and $3 \mathrm{~mL}$ of LB medium (without antibiotics) was inoculated with $15 \mu \mathrm{L}$ of ODadjusted culture. Samples were incubated at RT for at least 3 days. The LB medium was removed using a thin cannula and the biofilm (sticking to the tube wall) was stained with a $0.5 \%$ crystal violet solution (w/v in Aqua Bidest) for $20 \mathrm{~min}$. The crystal 
violet was removed and the biofilm was washed twice with $4 \mathrm{~mL}$ Aqua Bidest. The biofilm was scrubbed and flushed off the tube walls with a pipet tip and $96 \%$ alcohol solution. The absorption at $550 \mathrm{~nm}$ was determined. Samples which showed an OD > 1.0 were diluted 1:10 with $96 \%$ ethanol for measurement. For each strain 3 independent experiments were performed and statistical significance was analyzed by the Student's $t$ test (2-tailed, unpaired).

\section{Microscopy}

The bacterial strains ATCC 17978, ATCC 17978 ompA::Km, 29D2, and 29D2 ompA::Km were grown for $16 \mathrm{~h}$ at $37^{\circ} \mathrm{C}$ under constant shaking. One $\mu \mathrm{L}$ of each bacterial overnight culture was pipetted on a glass slide and analyzed under the bright field microscope (200 times magnification).

\section{Statistical analysis}

201

All experiments were performed at least 3 times. Comparison between groups was performed using GraphPad Prism 7 with Student's $t$ test (2-tailed, unpaired). P-values less than 0.05 were considered to be statistically significant.

\section{Results}

\section{Surface-associated motility}

Approximately 2,000 transposon mutants of ATCC 17978 were screened for surfaceassociated motility phenotypes and 30 were identified with motility defects. Previous studies were limited to the characterization of mutations in single strains. Here, to 
provide a comparative study, we introduced at least one mutation of every gene function category into 29D2 to get insight into strain-specific and species-specific traits.

To this end, surface-associated motility was analyzed on $0.5 \%$ agarose plates. The diameter $(\varnothing)$ of the surface motility spreading zone of 3 independent experiments was measured and analyzed (Fig. 1A and Suppl. Table S3). All selected motilitydeficient mutants of ATCC 17978 exhibited at least a 7-fold reduction of the spreading zone. Subsequently, DNA isolated from these transposon mutants was used to generate mutants in 29D2. All 29D2 mutants displayed a motility-deficient phenotype compared to the wildtype strain (Fig. 1B). Note that the surfaceassociated motility spreading zone of the wildtype ATCC 17978 (mean $\varnothing$ of $78 \mathrm{~mm}$ ) was more than twice as large as that of the 29D2 wildtype strain (mean $\varnothing$ of $30 \mathrm{~mm}$ ). Most ATCC 17978 mutants showed a 16-fold reduced surface-associated motility compared to the wildtype strain (Fig 2A), whereas the a1s_0806 (encoding an aminotransferase) mutant lacked almost any measurable surface-associated motility (mean $\varnothing$ of $1 \mathrm{~mm}$ ). 3 mutants, purH::Km (mean $\varnothing 10.25 \mathrm{~mm}$ ), 1970::Km (mean $\varnothing$ $8.75 \mathrm{~mm}$ ), and 3297::Km (mean $\varnothing 11 \mathrm{~mm}$ ), showed 10-fold reduced surfaceassociated motility. Most 29D2 mutants displayed a 4-fold reduction in their surfaceassociated motility. The most pronounced reduction in motility appeared in mutants purH::Km (mean $\varnothing 5 \mathrm{~mm})$, purF::Km (mean $\varnothing 3.75 \mathrm{~mm}$ ), and ddc::Km (mean $\varnothing 4.25$ $\mathrm{mm}$ ). The mutant purM::Km (mean $\varnothing$ of about $16 \mathrm{~mm}$ ) had the lowest reduction in surface-associated motility.

To summarize, all mutations initially identified in ATCC 17978 that conferred motility defects were also found to cause motility-deficient phenotypes when introduced into the orthologous genes of 29D2. 


\section{Pellicle biofilm formation}

237

238

The formation of pellicles, a specific form of biofilm, occurs at the air-liquid interface and is distinct from submerged biofilms $[39,44,45]$. A correlation between surfaceassociated motility and pellicle biofilm formation has been described for $A$. baumannii [39]. We examined the ability of our motility-deficient mutants to form pellicles. Pellicle biofilms were incubated 3 days, stained with a $0.5 \%$ crystal violet solution, and analyzed by OD measurements (Suppl. Table S4). Pellicle-biofilm formation in wildtype ATCC 17978 was measured to be about 8.6 at OD $550 \mathrm{~nm}$ (Fig. 2A). A broad spread between low and high pellicle-producing mutants was visible, ranging between a 1.8-fold increase to more than a 25 -fold decrease. For 15 of 30 mutants less than $67 \%$ of the wildtype-specific pellicle biomass was quantified (Table 1 and Fig. 2A). In the mutants carB::Km, 0414::Km, and prpF::Km a pellicle biomass less than $8 \%$ compared to the wildtype biomass was measured. This dramatic decrease was not observed by inactivation of the orthologous gene in the 29D2 background. In ATCC 17978, 8 mutants (purH::Km, purM::Km, purE::Km, 0530::Km, 3297::Km, galE::Km, 0806::Km, and $1055:: \mathrm{Km}$ ) were able to produce more pellicle biomass compared to the wildtype strain, of which the mutants $0530:: K m$, galE::Km, and 0806:: Km produced $50-80 \%$ more pellicle biomass compared to wildtype (Fig. 2A). 29D2 mutants only displayed small changes in pellicle biofilm formation compared to wildtype, with a range of the mutants' pellicle biomass production from a 1.3-fold increase to a 2.1-fold decrease. 13 of 21 tested 29D2 mutants did not display any significant change in their pellicle biofilm formation compared to the parental strain (Table 2). Deficiencies could be observed in the following 6 mutant strains: carB::Km, $1970:: K m$, ddc::Km, dat::Km, gidA::Km, and 3026::Km, which produced less than 
$70 \%$ of the 29D2 wildtype-specific pellicle biomass. Only the following 2 mutants produced significantly more pellicle biomass (Fig. 2B) compared to the wildtype strain: purH::Km (30\%) and galE::Km (38\%).

In summary, the ATCC 17978 parental strain produced more pellicle biofilms compared to 29D2. Conspicuous changes in biofilm formation could mainly be observed among ATCC 17978 mutants. Concordance of pellicle formation phenotypes between the mutants of both strains was limited suggesting that strainspecific traits that are independent of surface-associated motility influence pellicle biomass production.

\section{Bacterial growth}

The ability of motility-deficient mutants to grow as a planktonic culture under aeration was assayed. Growth curves and data for all tested strains are provided in supplementary Fig. S4 (ATCC 17978 mutants), supplementary Fig. S5 (29D2 mutants), and Table S5. For 17978, 22 of 30 tested mutant strains exhibited significant growth defects compared to the parental strain (Table 1). The most striking growth defects (Fig. 3A) were observed in the mutants defective in purine biosynthesis (purH::Km, purF::Km, purM::Km, and purE::Km), pyrimidine biosynthesis (carB::Km), and diaminopropane biosynthesis (ddc::Km and dat::Km). Only 8 of 30 tested mutant strains were able to grow without any defect compared to the parental strain (Table 1). By testing the 29D2 mutant strains we observed 13 of 21 strains with notable planktonic growth defects (Table 2). Within this group most striking defects were observed with mutations associated with purine biosynthesis (purH::Km, purF::Km, purM::Km, and purE::Km), pyrimidine biosynthesis (carB::Km), folate 
biosynthesis $(1566:: \mathrm{Km})$, and diaminopropane biosynthesis (ddc::Km and dat::Km). Additionally, galE::Km, comEC::Km, and prpF::Km mutants displayed strong growth deficiencies (Fig. 3B). The mutant ompA::Km showed growth comparable to the parental strain for up to $4 \mathrm{~h}$, reached a growth maximum of $2.5 \pm 0.28 \mathrm{OD}_{600} \mathrm{~nm}$ after $5 \mathrm{~h}$, but then slowly collapsed to $1.36 \pm 0.73$ after $9 \mathrm{~h}$. No growth defects were observed in 8 of 21 tested mutants (Table 2).

In summary, we found that genes involved in purine/pyrimidine and diaminopropane biosynthesis, oxidative stress, and propionate catabolism were crucial for growth of ATCC 17978 and 29D2 in LB medium.

\section{G. mellonella caterpillar infection}

To gain insight into a possible correlation between motility and virulence we made use of the G. mellonella infection model. Caterpillars were infected with $3 \times 10^{5} \mathrm{CFU}$ of different $A$. baumannii strains and the death of larvae was monitored over a time period of 5 days. G. mellonella infection of ATCC 17978 wildtype and mutant strains is shown in supplementary Fig. S6 and levels of significance for 5 days post-infection are presented in Table 1. A detailed listing of $p$-values for every monitored timepoint is provided in supplementary Table S6. After $24 \mathrm{~h}$ post-infection with the 17978 wildtype strain about $60 \%$ of larvae were dead. This number increased to over $80 \%$ of dead larvae after 5 days post-infection. 15 of 30 tested mutant strains displayed a significant attenuation in G. mellonella infection (Table 1). Another 4 mutant strains (purE::Km, 1624::Km, rpmG::Km, and $d d c:: K m$ ) showed some attenuation but this was not significant. The remaining 11 mutant strains did not display attenuation (Suppl. Fig. S6 and Table 1). Most pronounced attenuation was observed in strains 
carB::Km, metG::Km, ompA::Km, and galE::Km (Fig. 4A). These results suggest an important role for these genes in A. baumannii virulence. However, to exclude the possibility that attenuation could be due to decreased planktonic growth, we compared the caterpillar infection results to our bacterial growth data (Fig. 3, Suppl. Fig. S4, and Fig. S5). Among the above mentioned mutants, only the galE::Km mutant was not significantly affected in growth. Overall, we found that for 11 of 15 significantly attenuated mutant strains the caterpillar infection data could possibly be influenced by decreased growth rates (Table 1 and Fig. 3).

The G. mellonella infection with 29D2 wildtype and mutant strains data is shown in supplementary Fig. S7 and significance levels (for 5 days post-infection) are shown in Table 2. A detailed listing of p-values for every monitored timepoint is provided in supplementary Table S7. 11 of 21 29D2 mutants were significantly attenuated in the G. mellonella infection model (Suppl. Fig S7 and Table 2). Within this group the most pronounced attenuation was observed in strains carB::Km, ompA::Km, galE::Km, and comEC::Km (Fig. 4B). The mutant strains purE::Km, gidA::Km, and $0806:: K m$ showed some attenuation at 5 days post-infection but p-values ranged between $0.060-0.067$ (Suppl. Table S7). Interestingly, 8 of 11 significantly attenuated mutant strains (purH::Km, 1566::Km, carB::Km, ompA::Km, ddc::Km, comEC::Km, galE::Km, and $2761:: \mathrm{Km}$ ) manifested a growth deficiency compared to the parental strain (Suppl. Fig. S5 and Table 2).

In summary, concordant infection traits were observed for 12 mutants of both strains including mutants affected in purine/pyrimidine/folate biosynthesis. Among these 12 strains, most significant attenuation was observed for carB::Km, ompA::Km, and galE::Km. 
As a control, the CFUs were determined from the OD-adjusted bacterial cultures used for the infection experiments. To this end, OD-adjusted cultures were serially diluted and plated on nutrient agar. Colonies were counted after incubation for $18 \mathrm{~h}$ at $37^{\circ} \mathrm{C}$. Interestingly, for both ATCC 17978 ompA::Km and 29D2 ompA::Km mutants we observed 1-2 log scale lower CFU numbers compared to the OD-adjusted suspension (data not shown). Sticking of cells to the tube wall during the dilution process was minimized by using low-binding tubes (Eppendorf). When growing both ompA::Km mutants on agar plates we observed a very sticky colony texture upon touching with a glass rod. Based on these findings we examined the cell morphology of ompA::Km mutant strains under the microscope. A distinct cell elongation or chain formation of both ompA::Km mutant strains compared to their parental strains was observed (Supplementary Fig. S8).

\section{MIC Determination}

We aimed to elucidate the correlation between motility-deficient mutants and their sensitivity to the bactericidal antibiotics ampicillin and imipenem as well as to the bacteriostatic antibiotic tetracycline. For ATCC 17978, 18 of 30 mutants displayed a significant resistance to ampicillin compared to the parental strain. The highest MIC values were obtained in mutant strains $0414:: \mathrm{Km}$ (4-fold increase compared to the parental strain), 3026:: Km (4-fold increase), and 1566::Km (3.7-fold increase). The only mutant strain which showed decreased resistance (0.7-fold decrease) to ampicillin was aamA::Km (Table 3). By contrast, a significantly increased sensitivity to imipenem was observed in six (purE::Km, carB::Km, 1624::Km, rpmG::Km, 1970::Km, and aamA::Km) of the tested strains (Table 1). Furthermore, a significantly 
increased resistance to imipenem was observed in 4 of the tested mutant strains (ompA::Km, 3297::Km, 0806::Km, and 3026::Km). For tetracycline, we found 13 of 30 mutants to be significantly more sensitive compared to the parental strain. Only 2 of 30 mutant strains, purF::Km and galE::Km, displayed significantly increased resistance to tetracycline (Table 1). Next, we analyzed all 29D2 mutant strains with respect to the MIC values for ampicillin, imipenem, and tetracycline. A significantly increased sensitivity to ampicillin was observed in 15 of 21 tested mutant strains compared to wildtype (Table 2). The only strain with significantly increased resistance to ampicillin was $3026:: \mathrm{Km}$, with a 1.7-fold increased MIC value (Table 3). Another mutant strain with a 1.5-fold increased ampicillin MIC value, although not significant, was aamA::Km. Similar effects were observed for imipenem (Table 3). Here, strains 3026::Km and aamA::Km displayed significant resistance compared to the parental strain (Table 2). Increased sensitivity to imipenem was observed in 8 of 21 tested mutants. For the MIC values of tetracycline, we found the 3 mutant strains $1566:: \mathrm{Km}$ (3.6-fold decrease), comEC::Km (5.4-fold decrease), and prpF::Km (6.5-fold decrease) to be significantly more susceptible compared to the parental strain (Table 3). Only one mutant, dat::Km, was significantly more resistant to tetracycline with a 1.8-fold increase (Table 3). In conclusion, mutants from the 29D2 background predominantly showed increased sensitivity to all tested antibiotics. By contrast, many mutants of ATCC 17978 showed 376 increased resistance to ampicillin, but increased sensitivity to imipenem and 377 tetracycline. 


\section{Discussion}

Recently, A. baumannii was demonstrated to exhibit motility on semi-dry plates, with agar concentrations between $0.2-0.4 \%$, and motility was dependent on the type of agar that was used. Bacterial surface spreading was shown not to depend on type IV pili [26]. Here, we characterized 30 genes involved in $A$. baumannii surfaceassociated motility with respect to bacterial growth, pellicle biofilm formation, virulence, and antibiotic resistance. We discuss motility-deficient mutants with regards to their known/putative gene function in the bacterial cell (Fig. 5).

\section{Genes involved in purine/pyrimidine/folate biosynthesis}

In our study we identified 4 proteins involved in purine (pur) biosynthesis to be essential for A. baumannii surface-associated motility: PurH, PurF, PurM, and PurE (Tables 1 and 2). The decrease in surface motility of these mutants ranged from a 25-fold decrease in ATCC 17978 to a 2.1-fold decrease in 29D2 compared to their parental strains (Suppl. Table S3). In A. nosocomialis strain M2, EZ::Tn insertion in gene purK (a1s_2963) has been previously described to result in a 70\% reduction in surface motility compared to the parental strain [26]. Mutations in the genes purD, purF, purH, purL, and purM abolished $\mathrm{K}^{+}$-dependent colony spreading in Bacillus subtilis [46]. The pur genes were also demonstrated to be essential for biofilm formation in Bacillus cereus (purH and purD [47]; purA [48]; purA, purC, and purL [49]). Interestingly, our study revealed no defective role of pur genes in pellicle biofilm formation. In contrast, mutations purH::Km, purM::Km, and purE::Km in 17978 and purH::Km in 29D2 produced significantly more pellicle biomass than their parental strains (Tables 1 and 2). A pellicle proteome study in 17978 showed that the pur 
404

405

406

407

408

409

410

411

412

413

proteins were differentially expressed/accumulated under planktonic (PurH, PurF, and PurA), 1-day pellicle (PurM and PurB), and 4-day pellicle (PurD) growth conditions [44].

In addition to the motility deficiency, we found all tested pur mutants to display bacterial growth defects in LB media (Suppl. Figs. S4 and S5). For various bacteria, pur genes were identified to be required for bacterial growth in human serum including Enterococcus faecium (purL, purH, and purD) [50], E. coli (purA, C, D, E, F, $H, K, L$, and $M$ ), S. enterica (purA, $B, C, D, E, F, G$, and $H$ ), and $B$. anthracis (purE and purK) [51]. Due to the fact that all pur mutants displayed bacterial growth defects we expected these mutants to be attenuated in the G. mellonella infection, but we only found the 2 mutants ATCC 17978 purM::Km and 29D2 purH::Km had significant attenuation (Fig. 4). Purine biosynthesis mutants (purF, purD, and purL) in Burkholderia cenocepacia were also found to be attenuated in the G. mellonella infection model as well as in C. elegans and D. melanogaster infections [52]. De novo purine biosynthesis has also been shown to be required for virulence in ATCC 17978 (purF, purD, purN, purL, purM, purK, purE, purC, purP, and purO) in the mouse lung [53], and in several other bacteria such as Streptococcus pneumoniae (purE, purK, purC, and purL) [54], Bacillus anthracis (purH) [55], and Pasteurella multocida (purF) [56].

The pur mutants were tested for antibiotic sensitivity/resistance against ampicillin, imipenem, and tetracycline. For ampicillin MIC's we obtained very contrary results. The pur mutants of 29D2 showed increased sensitivity to ampicillin, but, except for purH::Km, the pur mutants of ATCC 17978 were significantly more resistant compared to their parental strain (Table 3). In $S$. aureus defective rifampicin persistence was shown for purB, purF, purH, and purM [57]. 
The $A$. baumannii gene a1s_2687 encodes the large subunit (carB) of carbamoylphosphate synthase and is arranged with the small subunit (carA) in the car $A B$ operon, which is required for the de novo synthesis of arginine and pyrimidines (reviewed in [58]), and in turn pyrimidines are known to be involved in biofilm formation in $P$. aeruginosa [59] and E. coli [60]. In A. baumannii, inactivation of carB caused a significantly decreased persistence in a mouse pneumonia model [53]. The contribution of carB to $A$. baumannii virulence was confirmed by our results, showing significant attenuation in both ATCC 17978 carB::Km and $29 \mathrm{D} 2$ carB::Km mutant strains (Fig. 4). Additionally, in a $P$. aeruginosa competition study against $B$. cepacia, K. pneumoniae, and $S$. aureus, the carB gene and hence uracil/pyrimidine biosynthesis was identified to be essential [61]. Inactivation of carB in ATCC 17978 and 29D2 resulted in the greatest phenotypic alterations in planktonic growth, pellicle biofilm formation, and G. mellonella caterpillar infection of all tested mutants (Tables 1 and 2). Interestingly, similar observations were also made for the gammaproteobacterium Xanthomonas citri subsp. citri. In that study, the knockout of carB resulted in a $70 \%$ decrease in biofilm formation, an extensive reduction in swimming motility, and alterations in bacterial growth [62]. CarB was also found to be required for growth of $E$. coli in human serum [51]. A motility-deficient phenotype was identified for the gene a1s_1566 (putative 6-pyruvoyl-tetrahydropterin synthase), involved in folate biosynthesis and thus crucial for biosynthesis of purines and 449 deoxythymidine monophosphate (Fig. 1). Here we observed an involvement in 450 virulence, bacterial growth, and pellicle biofilm formation (Tables 1 and 2). Taken 451 together, these findings suggest that purine and pyrimidine genes contribute to 452 important bacterial processes like motility, bacterial growth, pellicle biofilm formation, 
453

454

455

456

457

458

459

460

461

462

463

464

465

466

467

468

469

470

471

472

473

474

475

476

and virulence not only in Acinetobacter but also in well studied genera like Bacillus and Salmonella.

\section{Genes involved in alarmone/damage metabolism}

The A. baumannii genes a1s_0414 and a1s_1624 encode for an Ap5A pyrophosphatase and an Ap4A hydrolase (ApaH-like), respectively, and are proposed to be involved in depletion of putative alarmones/signaling molecules $[63,64]$ and/or damage metabolites $[65,66]$. Recent work suggests that dinucleoside polyphosphates can be used by RNA polymerases to initiate transcription and to act as 5'-RNA caps that may stabilize RNA, while ApaA-like hydrolases are able to remove these caps [67]. The Ap4A hydrolase knockout mutant a1s_1624::Km seems to play a role in $A$. baumannii surface motility and planktonic growth (Table 1 ). An E. coli Ap4A hydrolase $(\mathrm{apaH})$ knockout mutant was previously associated with decreased motility [68]. In Salmonella enterica adhesion and invasion capacity into epithelial cells was reduced for the $\triangle a p a H$ mutant [69]. Additionally, the a1s_1624::Km mutant exhibited increased sensitivity to imipenem (Table 1). Increased sensitivity of $\triangle \mathrm{apaH}$ mutants against kanamycin and streptomycin was also shown for ATCC 17978, E. coli, and P. aeruginosa [70], and decreased sensitivity of $\triangle a p a H$ mutants, in the form of persister cells, was found in E. coli [71]. Although we could not observe a significant impact of a1s_1624::Km on pellicle formation, others have shown A1S_1624 to be overproduced in pellicle cells in ATCC 17978 [44], and Ap4A metabolism impacts biofilm formation in Pseudomonas fluorescens [72]. The Ap5A pyrophosphatase knockout in ATCC 17978 resulted in a significant reduction in pellicle biofilm formation, significant attenuation of $G$. 
477 mellonella infection, and resistance against ampicillin (Table 1). Interestingly, in the corresponding a1s_0414::Km mutant of 29D2, only surface-associated motility was affected (Table 2).

In general, Ap4A and Ap5A are thought to be synthesized by aminoacyl-tRNA synthetases in the absence of tRNAs during amino acid activation. This process requires ATP and a cognate amino acid $[73,74]$. Providing a possible link, we found a methionyl-tRNA synthetase in our surface motility-deficient library (discussed below).

\section{Genes involved in RNA modification/regulation}

486

487

488

489

490

491

492

493

494

495

496

497

498

499

500

We found 3 genes involved in the regulation and/or modification of RNAs: metG (methionyl-tRNA synthetase, a1s_0778), rpmG (50S ribosomal protein L33, a1s_0447), and gidA (glucose-inhibited division protein A, a tRNA modification enzyme, a1s_2182). The deficiency in motility of gidA mutants has been described mainly for swarming motility in bacteria like Bacillus cereus [48], Serratia species SCBI [75], and Pseudomonas syringae [76]. In the present study, a gidA null allele in strains ATCC 17978 and 29D2 resulted in small decreases in their planktonic growth (Suppl. Fig. S4 and S5). Contrary results for $\Delta$ gidA bacterial growth has been reported (reviewed in [77]). Interestingly, proteomic analysis of A. baumannii planktonic and biofilm growth identified GidA only under biofilm growth conditions [78], while several studies reported the negative effect of gidA mutants on biofilm formation in different bacteria $[79,80]$. In the present study we also saw a significant reduction of the pellicle-biofilm formation in both gidA::Km mutants (Fig. 2). An essential role of gidA in pellicle-biofilm formation was also shown in Bacillus cereus [48]. While several GidA-associated virulence effects have been reported (reviewed 
501 in [77]) we did not see significant attenuation in the G. mellonella infection model

502 (Suppl. Figs. S6 and S7).

503 In contrast, the knockout of metG (a1s_0778) was associated with a significant

504 attenuation in the G. mellonella infection model (Fig. 4). Similarly, involvement of

505 metG in A. baumannii virulence was also shown in a mouse pneumonia model [53].

506 The metG::Km mutant revealed a significantly reduced ability to form pellicles (Fig.

507 2). Moreover, MetG was found to be more abundant in $A$. baumannii pellicle cells

508 than in planktonic cells [44]. In our study we found the metG::Km mutant to be more

509 sensitive to tetracycline (Table 1 ), which agrees with observations of amino acid

510 substitutions of MetG associated with increased antibiotic tolerance in Burkholderia

511 thailandensis [81] and E. coli $[82,83]$.

512 We observed increased sensitivity of the rpmG::Km mutant to imipenem and tetracycline (Table 1). This data is in line with a study which showed that a mitomycin

\section{Genes involved in oxidative stress}

The ATCC 17978 gene a1S_3366 is predicted to encode a gamma-glutamatecysteine ligase $(g s h A)$ which is required to synthesize glutathione (GSH), an antioxidant molecule that protects cells against oxidative stress [85,86]. Different studies observed a decrease in swarming [87], swimming [87,88], and twitching motility [88] of the $P$. aeruginosa $\Delta g s h A$ mutant compared to the parental strain.

522 Contrary results were found for the ability of $P$. aeruginosa $\Delta g s h A$ to form biofilms 523 (increased in [88] and decreased in [87]). We did not find any changes in pellicle 524 biofilm production compared to the parental strains for both of our gshA mutants (Fig. 
2). In Acinetobacter baylyi the knockout of gshA increased sensitivity to metronidazole and ciprofloxacin [89]. We observed an enhanced sensitivity to ampicillin for the 29D2 gshA::Km mutant, but the ATCC 17978 gshA::Km mutant observed for the ATCC 17978 gshA mutant strain, which agrees with other studies describing gshA mutants to be attenuated in $C$. elegans infection ( $P$. aeruginosa [90]) and a murine infection model (Salmonella [91]).

The $A$. baumannii gene a1s_0530 encodes for a rhodanese domain-containing protein, a putative sulfurtransferase, supposed to be involved in oxidative stress detoxification and sulfur metabolism [92-95]. The only knockout-related phenotype, besides surface-associated motility-deficiency, that we observed in ATCC 17978 was a significant increase in pellicle biofilm production (Fig. 2A). Finally, the involvement of oxidative stress response proteins in air-liquid pellicles has been described recently in a proteomic study of ATCC 17978 [44].

\section{Outer membrane proteins}

541 The gene a1s_3297 encodes a putative outer membrane protein and a1s_1970

542 encodes a putative membrane-associated Zn-dependent protease (RseP). Here we

543 show that both genes are involved in $A$. baumannii virulence, pellicle formation, and 544 antimicrobial resistance (Tables 1 and 2).

545 We found OmpA to be involved in A. baumannii surface-associated motility, which

546 has been described for the $A$. nosocomialis strain M2 by Clemmer et al. [26]. Several

547 studies have reported the involvement of OmpA in biofilm formation [96-98] and

548 OmpA, along with other outer membrane proteins, was observed to accumulate in $A$. 
549 baumannii pellicle cells compared to planktonic cells [44]. We found the ompA

550

551

552

553

554

555

556

557

558

559

560

561

562

563

564

565

566

567

568

569

570

571

572

573

knockout associated with a significant decrease in pellicle biofilm formation in ATCC

17978 but not in 29D2 (Fig. 2). For A. baumannii and a number of other pathogens,

OmpA has been identified as a virulence factor and its importance in bacterial pathogenicity has been shown recently (reviewed in [99]). For example, the loss of OmpA impaired virulence of $A$. baumannii in C. elegans [100] and Klebsiella pneumoniae virulence in G. mellonella [101]. In our study, the knockout of ompA in both tested strains significantly decreased the mutant's ability to kill G. mellonella caterpillars (Fig. 4). We observed 1-2 log scale lower CFU numbers (for both mutant strains) compared to the OD-adjusted suspension which was used to infect the caterpillars. This observation led us to examine the mutant's cell morphology by microscopy. We found the ompA::Km mutants exhibiting filamentous cell phenotypes in contrast to the parental strains (Suppl. Fig. S8). Filamentous cell morphologies are known to provide bacterial survival advantages, e.g. protection against phagocytosis, resistance against antibiotics, and enhanced response to environmental cues like quorum sensing [102]. In other bacteria, the loss of outer membrane proteins, like the Tol-Pal system or OmpA-like proteins, resulted in reduced membrane integrity and alterations in cell division $[103,104]$. OmpA is involved in the ability of $A$. baumannii to grow and persist in human serum $[11,105]$ and in the adherence and invasion of epithelial cells [106]. A resistance phenotype was only observed for the ATCC 17978 ompA::Km mutant strain. This mutant showed a 2-fold increase in MIC for imipenem compared to the parental strain (Table 3), correlating with the published finding that the A. baumannii OmpA C-terminus is important for resistance to antibiotics including imipenem [107]. 


\section{Genes involved in 1,3-diaminopropane biosynthesis}

575 As previously shown, mutations in the genes dat and $d d c$ resulted in a dramatic 576 reduction in surface-associated motility, but can be restored by supplementation with

577

578

\section{Genes involved in lipopeptide synthesis/export}

The genes a1s_0113 and a1s_0116 are involved in the synthesis and export of a lipopeptide and are part of an operon consisting of 8 genes $[26,108]$. The knockout of a1s_0113 (acyl-CoA dehydrogenase) in A. nosocomialis clinical isolate M2 resulted in a significant surface motility defect [26], which correlates with our observation in ATCC 17978 (Fig. 1A). We found both mutants to show similar pleiotropic effects in ATCC 17978 (Table 1). Additionally, other genes of this operon have been reported to be necessary for motility (a1s_0112 and a1s_0115 [39]), pellicle biofilm formation (a1s_0112 and a1s_0115 [39]; a1s_0114 [108]), and biofilm formation on abiotic surfaces (a1s_0114 [108,109]). A pellicle proteome analysis in ATCC 17978 found the proteins A1S_0112-A1S_0118, with the exception of A1S_0114, to accumulate in the pellicle [44]. Since the gene a1s_0116 encodes an RND superfamily transporter, it may thus play a role in multi-drug resistance. Deletion of a1s_0116 in ATCC 17978 resulted in significantly increased ampicillin resistance compared to the parental 
598 strain whereas no differences were observed for testing with imipenem and

599 tetracycline (Table 3). A transcriptomic study on imipenem-resistant ATCC 17978

600

601

602

603

604

605

606

607

608

609

610

611

612

613

614

615

616

617

618

619

620

cells showed decreased expression of genes from the a1s_0112-a1s_0119 cluster [110]. Clemmer et al. speculated that the lipopeptide synthesized from the a1s_0112a1s_0119 operon may act as a surfactant to promote motility, but they could not detect any surfactant activity in A. nosocomialis culture supernatants [26]. While we could not show a significant effect of a1s_0113 or a1s_0116 inactivation on virulence in G. mellonella, significant attenuation was observed in the same model for an a1s_0114 mutant [108]. No essential role of any of the a1s_0112-a1s_0119 genes in virulence was also found for strain AB5075 [111]. In conclusion, our data confirm findings by other groups $[26,39,109,108,44]$ indicating that genes of the a1s_0112a1s_0119 operon are essential for surface motility and pellicle biofilm formation in A. baumannii.

\section{Genes involved in DNA modification/repair/uptake}

We found 4 genes in our library to be involved in DNA modification, uptake, and recombination. The gene a1s_0222, designated as aamA, encodes a Type II N6adenine DNA methyltransferase $[112,113]$. Methylation is important for the regulation of various physiological processes $[114,115]$. We speculate the phenotype of both aamA mutants to represent strain-specific traits (Tables 1 and 2). In bacteria DNA methylation is the most studied epigenetic mechanism and the E. coli Dam protein is the most prominent orphan DNA adenine methyltransferase [116]. For other bacteria like S. enterica, Y. enterocolitica, and K. pneumoniae different phenotypes of dam 
621 mutants and dam overexpression were shown to affect motility, virulence, and other

622 traits (reviewed in [117]).

623

624

625

626

627

628

629

630

631

632

633

634

635

636

637

638

639

640

641

642

643

644

645

The $A$. baumannii gene a1s_2334 encodes an S-adenosyl-L-homocysteine hydrolase $(\operatorname{sahH})$, which takes part in the recycling of S-adenosyl-L-methionine (SAM). Here we show that inactivation of sahH in A. baumannii leads to pleiotropic effects such as strong motility deficiency, a significant attenuation in G. mellonella caterpillar infection, and increased antibiotic resistance (Table 1). Furthermore, we found the Holliday junction helicase subunit $A$ (ruvAl a1s_2587) to be important for $A$. baumannii surface-associated motility, pellicle biofilm formation, and antibiotic resistance in ATCC 17978 (Table 1).

We identified the gene a1s_2610 in our mutant library screening. Designated as comEC, this gene is involved in DNA uptake and incorporation of exogenous DNA into the genome. Phenotypically, a linkage between motility and natural transformation competence was shown in that $A$. baumannii can take up DNA while moving along wet surfaces [16] and its transformability is influenced by motilitydetermining parameters such as agarose concentration [41]. Genetically this interrelationship was illustrated by abolished twitching motility and natural transformation competence of comEC knockout mutants in A. baumannii strains 07095 and 07-102, and a defect in surface-associated motility was ascribed for the ATCC 17978 comEC::Km mutant [16]. Deficiency in twitching motility has also been shown for $\triangle$ comEC in Thermus thermophilus [118]. Our results confirmed surfaceassociated motility deficiency in the 29D2 comEC::Km mutant strain (Fig. 2). Deficiency in twitching motility was also shown for $\triangle$ comEC in Thermus thermophilus [118]. A striking attenuation in G. mellonella caterpillar infection for the comEC::Km mutants in both 17978 and 29D2 was observed (Fig. 4), similar to attenuation of 
comEC::Km mutant derivatives of A. baumannii strains DSM 30011, 07-102, and 07095 [16]. In Listeria monocytogenes, comEC was demonstrated to be involved in phagosomal escape, intracellular growth, and virulence [119]. However, com genes have been reported to be involved in bacterial biofilm formation [120], which we could not confirm for our comEC::Km mutant strains (Fig. 2).

\section{Other genes}

The gene a1s_0065 encodes a UDP-glucose 4-epimerase (galE) and is predicted to play a role in capsule and lipopolysaccharide biosynthesis [121]. Capsules are important virulence factors in A. baumannii [122]. In this study, a knockout of galE resulted in a reduced motility phenotype in ATCC 17978 and 29D2 (Fig. 1). The involvement of lipopolysaccharides in Acinetobacter surface motility has recently been shown for the gene $r m / B$ which is part of the O-antigen in Gram-negative bacteria [26]. A proteomic study of $A$. baumannii revealed GalE to be only expressed in biofilm growth mode [78]. Additionally, multiple studies have revealed that UDPglucose 4-epimerases play a role in biofilm formation, including in Sinorhizobium meliloti [123], Vibrio cholerae [124], Bacillus subtilis [125], and Thermus thermophiles [126]. The knockout of galE resulted in a significant increase in pellicle biomass production for both mutants compared to their parental strains (Fig. 2). Similar observations were also made for a galE mutant in Haemophilus parasuis [127] and Porphyromonas gingivalis [128]. Moreover, other proteins necessary for the catabolism of D-galactose (Leloir pathway), GalM and GalU, were found to be upregulated in A. baumannii biofilms [129]. Infection of G. mellonella caterpillars with the galE::Km mutants resulted in a significant attenuation. The caterpillar survival rate 
5 days post infection was $98.9 \%$ for the ATCC 17978 galE::Km mutant and $95.8 \%$ for 29D2 galE::Km (Fig. 4). Similarly, a significant decrease in persistence in a mouse pneumonia model of $A$. baumannii was previously reported for the a1s_0065 mutant [53]. Several other studies demonstrated UDP-glucose 4-epimerases to be involved in virulence/pathogenesis, for example in Bacillus anthracis [130], Streptococcus iniae [131], and the plant-pathogenic fungus Leptosphaeria maculans [132]. In our study, we observed a resistance phenotype for the ATCC $17978 \mathrm{galE}:: \mathrm{Km}$ mutant to ampicillin and tetracycline. By contrast, the 29D2 galE::Km mutant showed significant sensitivity to ampicillin compared to the parental strain (Table 3). The galE mutant in Porphyromonas gingivalis was shown to be significantly more susceptible to benzylpenicillin, oxacillin, cefotaxime, imipenem, and vancomycin compared to the wildtype [128] and involvement of UDP-glucose 4-epimerases in antibiotic resistance/sensitivity was reported for several other bacteria [133-135].

The gene a1s_0806 encodes for an adenosylmethionine-8-amino-7-oxononanoate aminotransferase (bioA), belonging to the acetyl ornithine aminotransferase family, which is part of the pyridoxal phosphate-dependent aspartate aminotransferase superfamily. BioA is part of the biotin biosynthesis pathway and biotin is essential for cell metabolism in prokaryotes and eukaryotes, and only bacteria and plants can synthesize biotin de novo [136-138]. Inactivation of a1s_0806 in ATCC 17978 resulted in the strongest surface motility defect (Fig. 1) and the greatest pellicle biomass production of all tested mutants (Fig. 2). In contrast, the mutant's ability to kill G. mellonella caterpillars was not significant affected (Suppl. Figs. S6 and S7). Other studies in $M$. tuberculosis have demonstrated bioA to be essential for establishment of infection and persistence in mice [139]. 
A knockout of gene a1s_1055, encoding a LysM peptidoglycan-binding domaincontaining lytic transglycosylase, resulted in a significantly increased pellicle biomass production. Similar to our findings, mutation of lytic transglycosylase (A1S_3027) in A. nosocomialis strain M2 was found to exhibit surface motility deficiency [26]. A1S_1055 seems to play a role in $A$. baumannii virulence, since mutants of both parental backgrounds led to attenuation in the G. mellonella infection assay (Fig. 4).

The gene a1s_2761 encodes for a 2-methylaconitate cis-trans isomerase (PrpF), involved in the 2-methylcitric acid cycle and propionate catabolism. The inactivation of prpF in 17978 resulted in one of the most reduced pellicle formation phenotypes of all tested mutant strains (Fig. 2), which correlates with the previous finding that PrpF accumulated in mature 4-days pellicles in 17978 [44]. The mutant's virulence capacity was not significantly affected (Suppl. Fig. S6). In contrast, the 29D2 prpF::Km mutant strain displayed a significant attenuation in the G. mellonella infection model (Fig. 4) but did not affect pellicle biofilm formation (Fig. 2).

The $A$. baumannii gene a1s_3026 is predicted to encode a secreted ribonuclease T2 family protein (RNase T2-family). In the A. baumannii strain 98-37-09 a deficiency in surface motility for the a1s_3026 knockout was previously reported [34]. Additionally, Jacobs et al. indicated that the a1s_3026 mutant showed reduced colonization on abiotic surfaces like glass, polystyrene, and stainless steel, and that the a1s_3026 knockout was shown to be associated with decreased expression of genes involved in motility and biofilm formation [34]. Despite the deficiency in surface-associated motility we observed a significant decrease in pellicle biofilm formation (Tables 1 and 2). Interestingly, A1S_3026 was shown to be involved in A. baumannii colistin resistance [140] and both $3026:: \mathrm{Km}$ mutant strains exhibited elevated resistance values for ampicillin and imipenem (Table 3) . 
The A. baumannii gene a1s_3129 encodes for a succinylarginine dihydrolase (astB) and is involved in the arginine succinyltransferase (AST) pathway [141]. In a mouse pneumonia model of $A$. baumannii, the astB insertion caused a significant decrease in persistence [53]. However, we did not observe a significant attenuation in the G. mellonella infection model (Table 1). Furthermore, we observed a significant reduction of pellicle formation in the astB::Km mutant (Fig. 2A). This is in line with an accumulation of AstB in ATCC 17978 pellicle cells described previously [44].

\section{G. mellonella caterpillar infection}

The G. mellonella caterpillar, which is an established insect model system for bacterial infections [142], was used to study virulence traits of the motility-deficient mutants. A study on virulence and resistance to antibiotic and environmental stress analyzed 250,000 A. baumannii AB5075 transposon mutants for growth within G. mellonella larvae, and TnSeq experiments identified 300 genes essential for growth [111]. When comparing with these results, we could not identify concordant genes in our library, but we found that main categories of genes do match. For example we found galE to be essential and in AB5075 numerous genes involved in structure and function of the cell envelopment were found to be required for growth in G. mellonella [111]. Conversely, for example, the gidA::Km mutant was not attenuated in G. mellonella infection in our study (Suppl. Fig. S6 and Fig. S7), but was stated to be essential for growth of AB5075 in G. mellonella [111]. It is known that AB5075 is more virulent than ATCC 17978 [143,111], therefore, comparative studies are needed to unravel strain-specific and species-specific traits. 


\section{Limitations}

While our study highlights the need for comparative studies of specific mutant phenotypes in different strains to distinguish strain-specific from species-specific traits, it is clear that the two strains studied in detail here do not provide a sufficient basis to deduce such insight. Such comparative studies in combination with genomebased analyses may pave the way for the identification of species-specific traits and, ultimately, novel target sites.

The use of marker-based mutagenesis and naturally competent strains to efficiently generate sets of mutants in different strains has its shortcomings as recombination events are not necessarily limited to the site of the marker gene. Apart from homology-based recombination events, transfer of mobile genetic elements and even illegitimate recombination events may occur $[144,145]$ and could corrupt the mutants' phenotypes. A few of the mutations described in this study have been partially characterized previously using additional strains (ddc, dat, comEC, and aamA for example $[16,33,112])$. However, repetitive construction of the same mutants did not lead to significant phenotype variation arguing against a high frequency of such corrupting side-effects. The ability to rapidly reconstruct mutants is an advantage of this method which can allow for confirmation of mutant phenotypes.

Complementation experiments and site-specific deletion mutagenesis would exclude polar effects of the transposon insertions and help to verify the contribution of each gene. In support of the specificity of our findings, we found many groups of related mutants (e.g. purine and pyrimidine biosynthesis) and identified multiple linkages to motility mutants described in other organisms. 
We could not achieve a saturated mutant library which indicates that surfaceassociated motility is probably under control of additional genes yet to be discovered. Our attempts were limited by the poor transformability of ATCC 17978 with the transposome complex, and by the transposition not being completely unbiased so that we obtained several insertion events repeatedly and independently.

\section{Conclusion}

In this study we made use of a previously generated A. baumannii ATCC 17978 EZ$\mathrm{Tn}^{\mathrm{TM}}<\mathrm{KAN}-2>$ transposon mutant library [33] to screen for surface-associated motility-deficient mutants. We identified 30 genes involved in surface motility. All tested mutants originally identified as motility-deficient in strain ATCC 17978 also displayed a motility-deficient phenotype in the A. baumannii white stork isolate 29D2. Some of these genes have already been linked to motility in A. baumannii (e.g. comEC, a1s_0113, and a1s_0116) or other bacteria (e.g. carB and gidA), but some of our findings represent new insights into requirements for surface-associated motility. Furthermore, we analyzed these mutants with respect to bacterial growth, pellicle biofilm formation, virulence in G. mellonella infection, and antibiotic resistance and used the naturally competent strain 29D2 to indicate whether the mutations showed strain-specific or species-specific traits. In summary, we can state that mutations in genes involved in purine/pyrimidine/folate biosynthesis are essential for all tested categories. Mutants that targeted RNA modification/regulation seem to mainly play a role in motility and pellicle formation. The discovery of novel genes required for surface-associated motility in A. baumannii demonstrates that more work is required to further define its genetic basis. 

made available under aCC-BY 4.0 International license.

791 Conflict of Interest

792 The authors declare that they have no conflict of interest.

793 
A
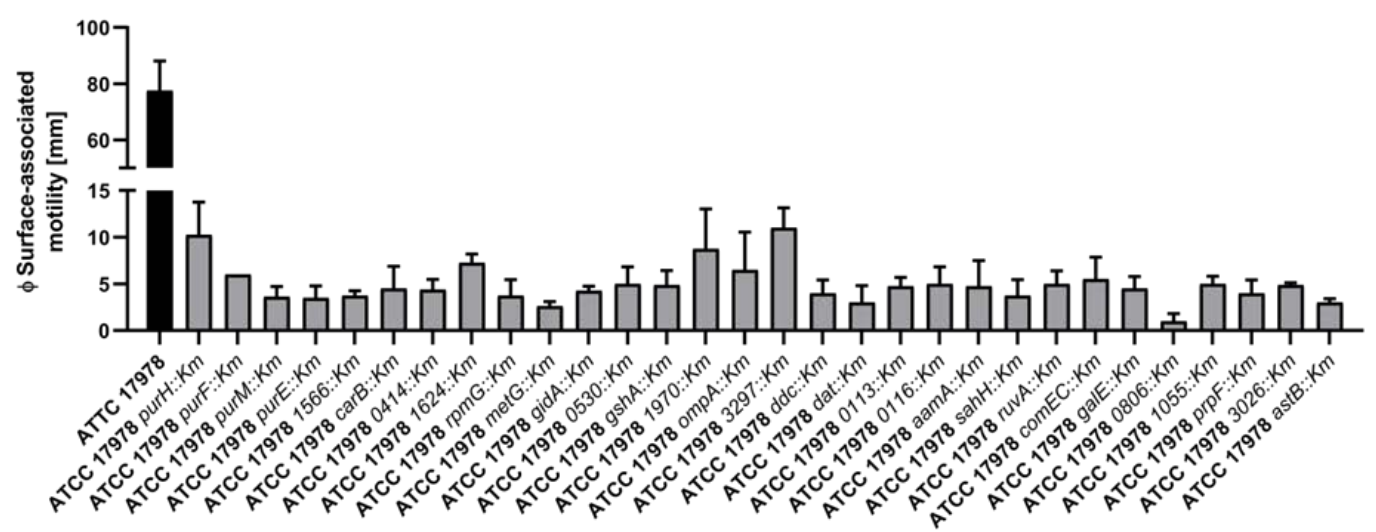

B

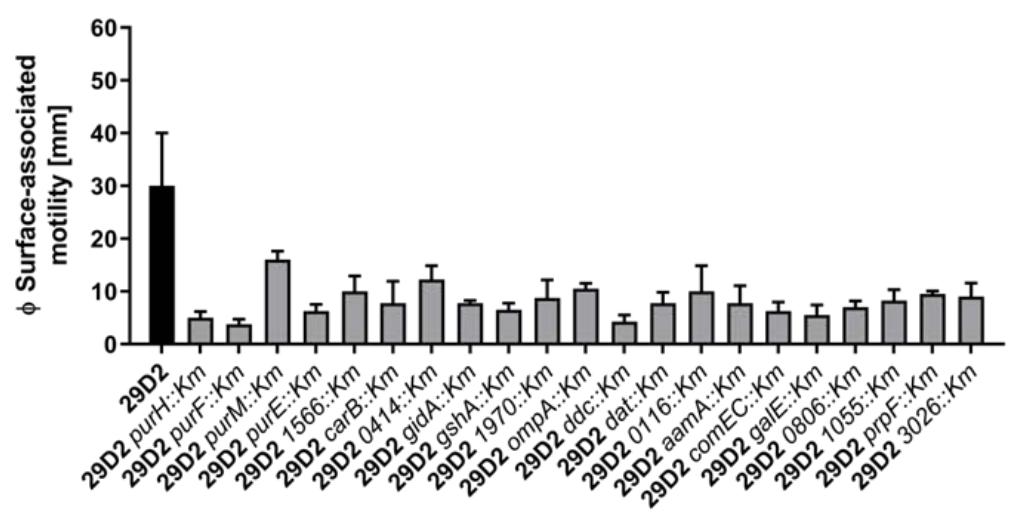

Fig. 1. ATCC 17978 mutants (A) and 29D2 mutants (B) deficient in surface-

associated motility. Wildtypes and mutants of strains ATCC 17978 and 29D2 were inoculated on motility plates. Plates were incubated for $16 \mathrm{~h}$ at $37^{\circ} \mathrm{C}$. The diameter $(\varnothing)$ of the surface-associated motility spreading zone was measured and triplicates 
A
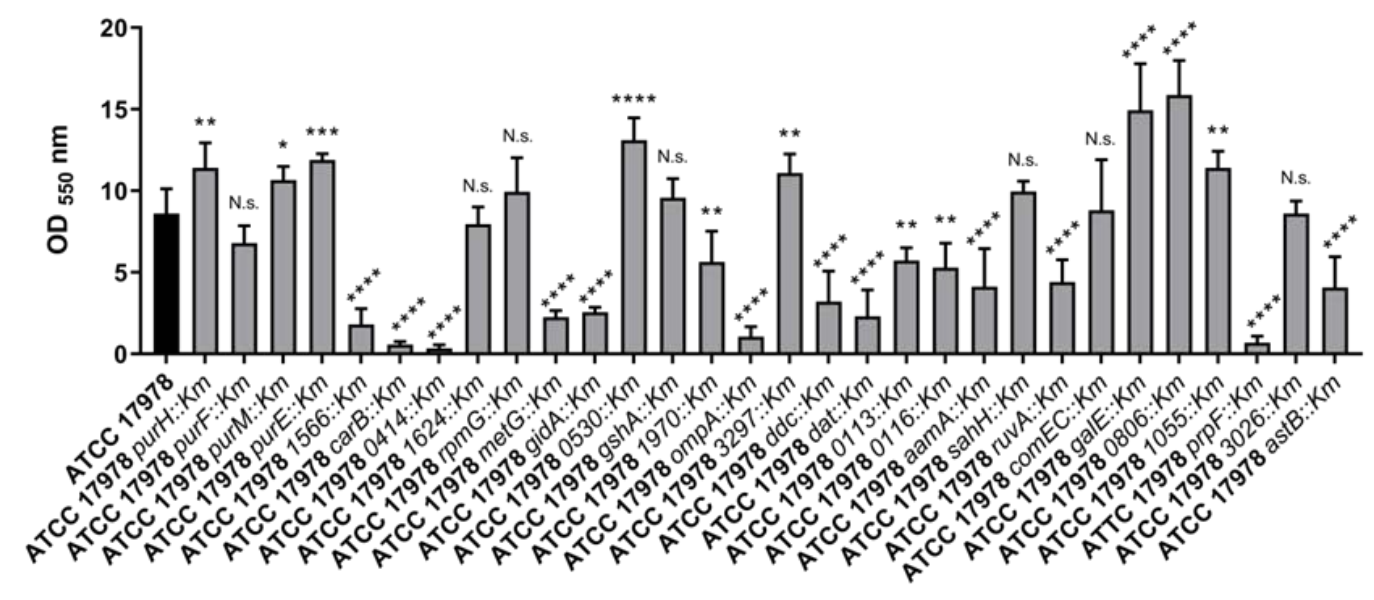

B

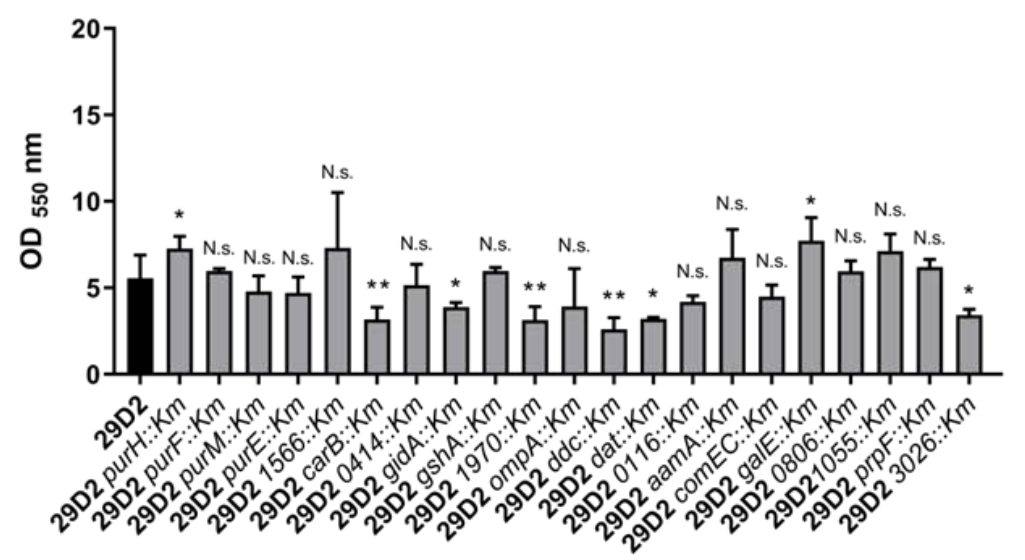

Fig. 2. Pellicle biofilm formation of ATCC 17978 wildtype and mutants (A) and was scrubbed and flushed off the tube walls and the absorption was determined at $550 \mathrm{~nm}$. For each strain 3 independent experiments were performed and statistical significance was analyzed by the Student's $t$ test (2-tailed, unpaired). Significance as 810 indicated: ${ }^{*}, \mathrm{p}$-value $\leq 0.05 ;{ }^{* *}, \mathrm{p}$-value $\leq 0.01 ;{ }^{* * *}, \mathrm{p}$-value $\leq 0.001 ;{ }^{* * *}, \mathrm{p}$-value $\leq$ 0.0001. 
A

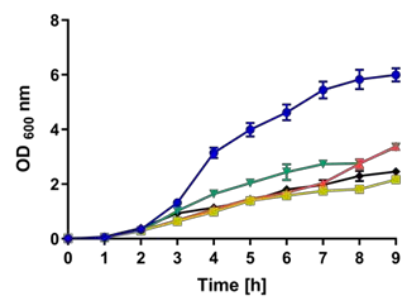

$\rightarrow$ ATCC 17978

- ATCC 17978 purH::Km

- ATCC 17978 purF::Km

- ATCC 17978 purM:: Km

$\rightarrow$ ATCC 17978 purE::Km

B

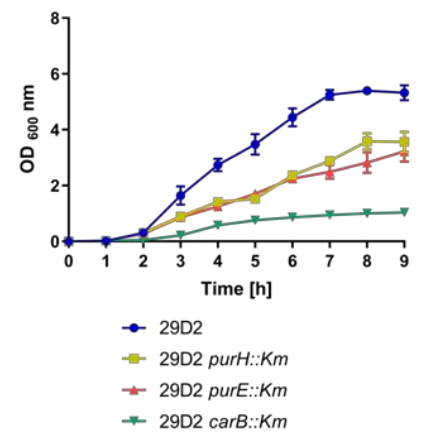

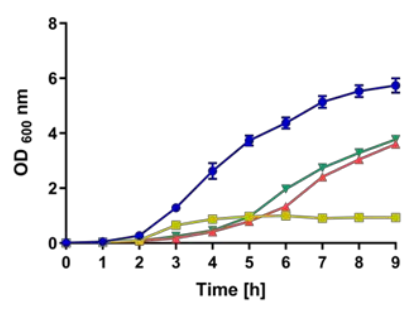

- ATCC 17978

- ATCC 17978 carB:: Km

- ATCC 17978 ddc:: Km

* ATCC 17978 dat: Km

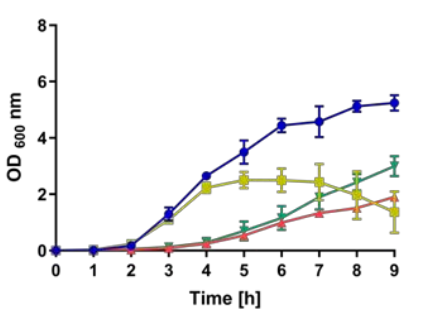

$\rightarrow 29 \mathrm{D} 2$

- $29 \mathrm{D} 2$ ompA::Km

- $29 \mathrm{D} 2 \mathrm{ddc::Km}$

- 29D2 dat: $: \mathrm{Km}$

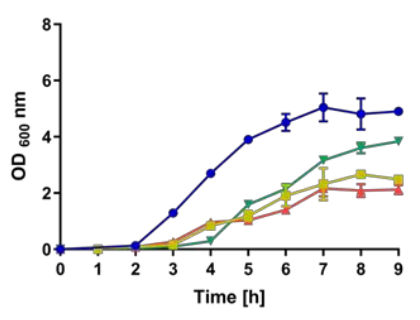

$\rightarrow 29 \mathrm{D} 2$

- $29 \mathrm{D} 2$ galE: $: \mathrm{Km}$

- $29 \mathrm{D} 2$ prpF:: Km

- 29D2 comEC::Km strain data obtained from 3 independent cultures grown on the same day were averaged and represented by the mean \pm SD. Growth defects compared to wildtype ATCC 17978 were observed for mutants that are involved in purine, pyrimidine, and diaminopropane biosynthesis (A). In strain 29D2, growth defects were observed for mutants involved in purine/pyrimidine/folate and diaminopropane biosynthesis, and for mutants galE::Km, ompA::Km, and prpF::Km (B). See Supplementary Figs. S4 and S5 for growth curves of all strains described in this study. 
A

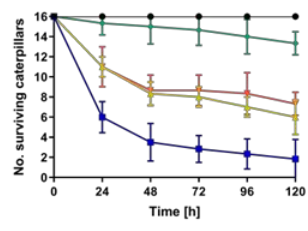

- PBS

- ATCC 17978

- ATCC 17978 1566: Km

B

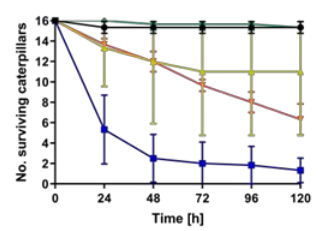

- PBS
- 2902

- 2902 purt: $\mathrm{Km}$

$+29021566: \mathrm{Km}$
$+\quad 2902$ carB $* \mathrm{Km}$

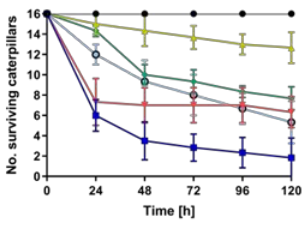

- PBS
- ATCC 17978

- ATCC 17978 metG:Km

- ATCC 17978 gshA.K

- ATCC 17978 1970:K

- ATCC 17978 1970:Km

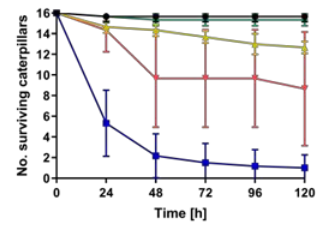

- PBS
-2902

- $29 \mathrm{DD} 2$ ompA: Km

$+29 D 2$ ddc:: Km
$+\quad 29 D 2$ galE: $\mathrm{Km}$

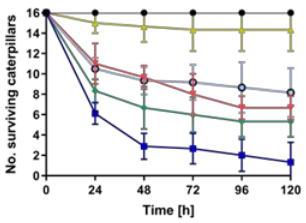

- PBS

- ATCC 17978

- ATCC 17978 ompA.Km

- ATCC 17978 dat: $: \mathrm{Km}$

-. ATCC 17978 aamA:Km

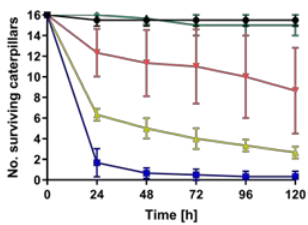

- PBS
-2902

- 29D2
$+\quad 29 D 2$ aama $\mathrm{Km}$

+ 29D2 aamA: $1055 \mathrm{Km}$

- 2902 comEC: $\mathrm{Km}$

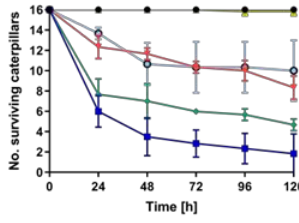

- PBS

- ATCC 17978

- ATCC 17978 gale: Km

- ATCC 17978 sahH:Km

- ATCC 17978 sahH: Km

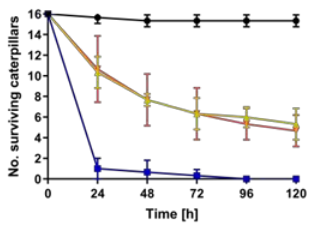

- PBS

\begin{tabular}{l} 
- $29 \mathrm{D} 2$ \\
$+29 \mathrm{D} 2 \mathrm{prFF}: \mathrm{Km}$ \\
\hline$-29 D 2$
\end{tabular}

(B) in the G. mellonella caterpillar infection model. Caterpillars were infected with

$3 \times 10^{5} \mathrm{CFU}$ of $A$. baumannii strains as indicated. Sterile PBS (black lines) was used experiments were averaged and represented by the mean \pm SD. In strain ATCC 17978, 15 of 30 mutants showed a significant attenuation at 5 days post-infection

833 (see Table 1 for $p$-values) compared to the wildtype strain (A). In strain 29D2, 11 of described in this study. 


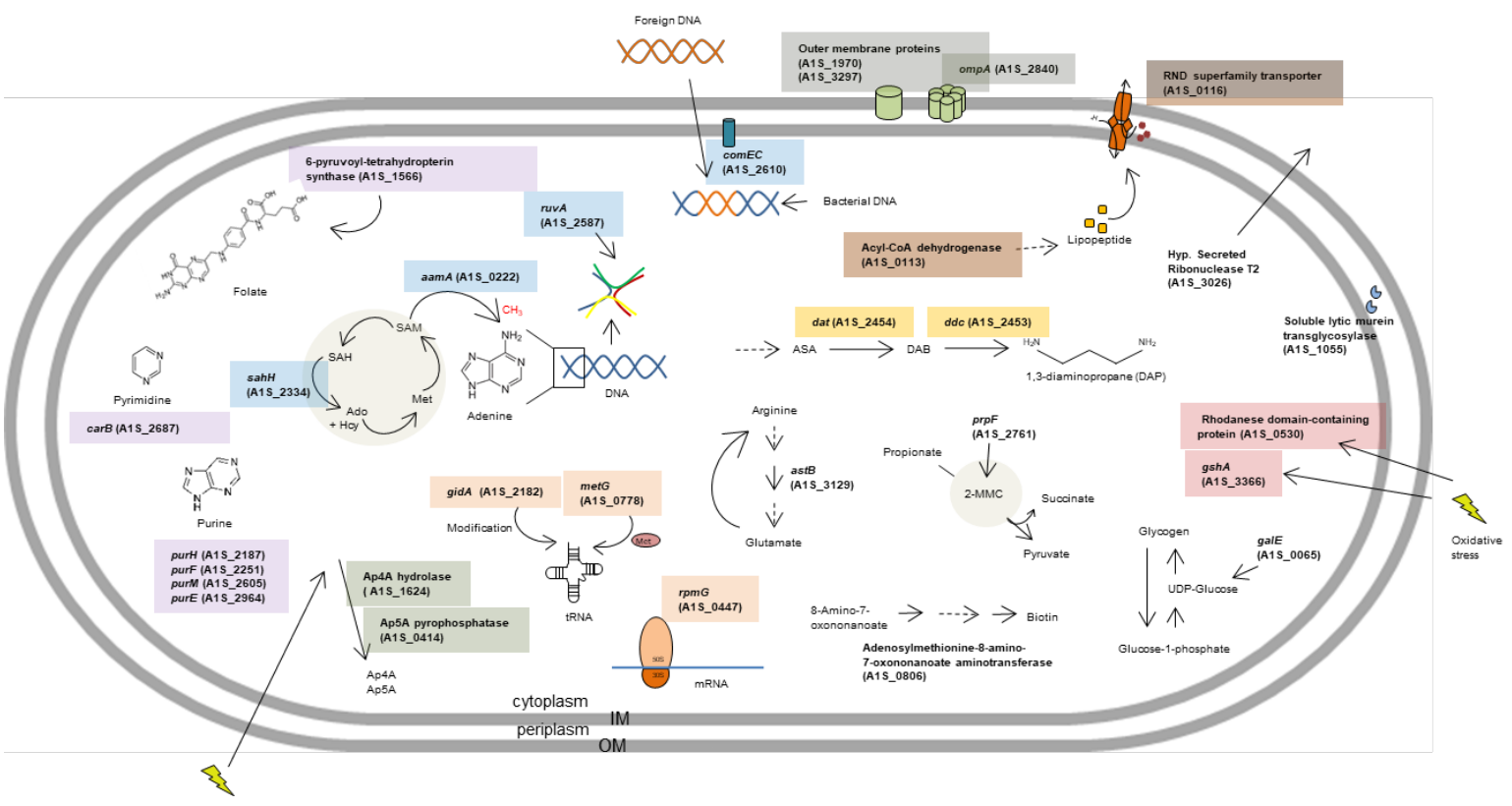

Fig. 5 Genes inactivated in A. baumannii ATCC 17978 mutants with a surface-

bacterial cell. A common color code indicates that mutants belong to the same 


\section{References}

849 1. Baumann P (1968) Isolation of Acinetobacter from soil and water. J Bacteriol 96 (1):39-42

850 2. Peleg AY, Seifert H, Paterson DL (2008) Acinetobacter baumannii: emergence of a successful pathogen. Clin Microbiol Rev 21 (3):538-582. doi:10.1128/CMR.00058-07

3. Harding CM, Hennon SW, Feldman MF (2018) Uncovering the mechanisms of Acinetobacter baumannii virulence. Nat Rev Microbiol 16 (2):91-102. doi:10.1038/nrmicro.2017.148

4. Vincent JL, Rello J, Marshall J, Silva E, Anzueto A, Martin CD, Moreno R, Lipman J, Gomersall C, Sakr Y, Reinhart K, Investigators EIGo (2009) International study of the prevalence and outcomes of infection in intensive care units. JAMA 302 (21):2323-2329. doi:10.1001/jama.2009.1754

5. Landman D, Bratu S, Kochar S, Panwar M, Trehan M, Doymaz M, Quale J (2007) Evolution of antimicrobial resistance among Pseudomonas aeruginosa, Acinetobacter baumannii and Klebsiella pneumoniae in Brooklyn, NY. J Antimicrob Chemother 60 (1):78-82. doi:10.1093/jac/dkm129

6. Tognim MC, Andrade SS, Silbert S, Gales AC, Jones RN, Sader HS (2004) Resistance trends of Acinetobacter spp. in Latin America and characterization of international dissemination of multidrug resistant strains: five-year report of the SENTRY Antimicrobial Surveillance Program. Int J Infect Dis 8 (5):284-291. doi:10.1016/j.ijid.2003.11.009

7. Giammanco A, Cala C, Fasciana T, Dowzicky MJ (2017) Global Assessment of the Activity of Tigecycline against Multidrug-Resistant Gram-Negative Pathogens between 2004 and 2014 as Part of the Tigecycline Evaluation and Surveillance Trial. mSphere 2 (1). doi:10.1128/mSphere.00310-16

8. Tacconelli E, Carrara E, Savoldi A, Harbarth S, Mendelson M, Monnet DL, Pulcini C, Kahlmeter G, resistant bacteria and tuberculosis. Lancet Infect Dis 18 (3):318-327. doi:10.1016/S14733099(17)30753-3

9. Roca I, Espinal P, Vila-Farres X, Vila J (2012) The Acinetobacter baumannii Oxymoron: Commensal Hospital Dweller Turned Pan-Drug-Resistant Menace. Front Microbiol 3:148. doi:10.3389/fmicb.2012.00148

10. Giannouli M, Antunes LC, Marchetti V, Triassi M, Visca P, Zarrilli R (2013) Virulence-related traits of epidemic Acinetobacter baumannii strains belonging to the international clonal lineages I-III and to the emerging genotypes ST25 and ST78. BMC Infect Dis 13:282. doi:10.1186/1471-2334$13-282$ 
11. Antunes LC, Imperi F, Carattoli A, Visca P (2011) Deciphering the multifactorial nature of Acinetobacter baumannii pathogenicity. PLoS One 6 (8):e22674. doi:10.1371/journal.pone.0022674

12. Jawad A, Seifert H, Snelling AM, Heritage J, Hawkey PM (1998) Survival of Acinetobacter baumannii on dry surfaces: comparison of outbreak and sporadic isolates. J Clin Microbiol 36 (7):1938-1941

13. Wagenvoort JH, Joosten EJ (2002) An outbreak Acinetobacter baumannii that mimics MRSA in its environmental longevity. J Hosp Infect 52 (3):226-227. doi:10.1053/jhin.2001.1294

14. Greene C, Vadlamudi G, Newton D, Foxman B, Xi C (2016) The influence of biofilm formation and multidrug resistance on environmental survival of clinical and environmental isolates of Acinetobacter baumannii. Am J Infect Control 44 (5):e65-71. doi:10.1016/j.ajic.2015.12.012

15. Eijkelkamp BA, Stroeher UH, Hassan KA, Elbourne LD, Paulsen IT, Brown MH (2013) H-NS plays a role in expression of Acinetobacter baumannii virulence features. Infect Immun 81 (7):25742583. doi:10.1128/IAI.00065-13

16. Wilharm G, Piesker J, Laue M, Skiebe E (2013) DNA uptake by the nosocomial pathogen Acinetobacter baumannii occurs during movement along wet surfaces. J Bacteriol 195 (18):41464153. doi:10.1128/JB.00754-13

17. Harding CM, Tracy EN, Carruthers MD, Rather PN, Actis LA, Munson RS, Jr. (2013) Acinetobacter baumannii strain M2 produces type IV pili which play a role in natural transformation and twitching motility but not surface-associated motility. MBio 4 (4). doi:10.1128/mBio.00360-13

18. Harshey RM (2003) Bacterial motility on a surface: many ways to a common goal. Annu Rev Microbiol 57:249-273. doi:10.1146/annurev.micro.57.030502.091014

19. Jarrell KF, McBride MJ (2008) The surprisingly diverse ways that prokaryotes move. Nat Rev Microbiol 6 (6):466-476. doi:10.1038/nrmicro1900

20. Mattick JS (2002) Type IV pili and twitching motility. Annu Rev Microbiol 56:289-314. doi:10.1146/annurev.micro.56.012302.160938

21. Merz AJ, So M, Sheetz MP (2000) Pilus retraction powers bacterial twitching motility. Nature 407 (6800):98-102. doi:10.1038/35024105

22. Skerker JM, Berg HC (2001) Direct observation of extension and retraction of type IV pili. Proc Natl Acad Sci U S A 98 (12):6901-6904. doi:10.1073/pnas.121171698

23. Wall D, Kaiser D (1999) Type IV pili and cell motility. Mol Microbiol 32 (1):1-10. doi:10.1046/j.1365-2958.1999.01339.x

24. Henrichsen J (1984) Not gliding but twitching motility of Acinetobacter calcoaceticus. J Clin Pathol 37 (1):102-103. doi:10.1136/jcp.37.1.102-b 
25. McBride MJ (2010) Shining a light on an opportunistic pathogen. J Bacteriol 192 (24):6325-6326. doi:10.1128/JB.01141-10

26. Clemmer KM, Bonomo RA, Rather PN (2011) Genetic analysis of surface motility in Acinetobacter baumannii. Microbiology 157 (Pt 9):2534-2544. doi:10.1099/mic.0.049791-0

27. Henrichsen J, Blom J (1975) Correlation between twitching motility and possession of polar fimbriae in Acinetobacter calcoaceticus. Acta Pathol Microbiol Scand B 83 (2):103-115. doi:10.1111/j.1699-0463.1975.tb00078.x

28. Eijkelkamp BA, Stroeher UH, Hassan KA, Papadimitrious MS, Paulsen IT, Brown MH (2011) Adherence and motility characteristics of clinical Acinetobacter baumannii isolates. FEMS Microbiol Lett 323 (1):44-51. doi:10.1111/j.1574-6968.2011.02362.x

29. Barker J, Maxted H (1975) Observations on the growth and movement of Acinetobacter on semisolid media. J Med Microbiol 8 (3):443-446. doi:10.1099/00222615-8-3-443

30. Mussi MA, Gaddy JA, Cabruja M, Arivett BA, Viale AM, Rasia R, Actis LA (2010) The opportunistic human pathogen Acinetobacter baumannii senses and responds to light. J Bacteriol 192 (24):6336-6345. doi:10.1128/JB.00917-10

31. Eijkelkamp BA, Hassan KA, Paulsen IT, Brown MH (2011) Investigation of the human pathogen Acinetobacter baumannii under iron limiting conditions. BMC Genomics 12:126. doi:10.1186/1471-2164-12-126

32. McQueary CN, Kirkup BC, Si Y, Barlow M, Actis LA, Craft DW, Zurawski DV (2012) Extracellular stress and lipopolysaccharide modulate Acinetobacter baumannii surface-associated motility. J Microbiol 50 (3):434-443. doi:10.1007/s12275-012-1555-1

33. Skiebe E, de Berardinis V, Morczinek P, Kerrinnes T, Faber F, Lepka D, Hammer B, Zimmermann O, Ziesing S, Wichelhaus TA, Hunfeld KP, Borgmann S, Grobner S, Higgins PG, Seifert H, Busse HJ, Witte W, Pfeifer Y, Wilharm G (2012) Surface-associated motility, a common trait of clinical isolates of Acinetobacter baumannii, depends on 1,3-diaminopropane. Int J Med Microbiol 302 (3):117-128. doi:10.1016/j.jjmm.2012.03.003

34. Jacobs AC, Blanchard CE, Catherman SC, Dunman PM, Murata Y (2014) An ribonuclease T2 family protein modulates Acinetobacter baumannii abiotic surface colonization. PLoS One 9 (1):e85729. doi:10.1371/journal.pone.0085729

35. Heindorf M, Kadari M, Heider C, Skiebe E, Wilharm G (2014) Impact of Acinetobacter baumannii superoxide dismutase on motility, virulence, oxidative stress resistance and susceptibility to antibiotics. PLoS One 9 (7):e101033. doi:10.1371/journal.pone.0101033 
36. Ahmad I, Nygren E, Khalid F, Myint SL, Uhlin BE (2020) A Cyclic-di-GMP signalling network regulates biofilm formation and surface associated motility of Acinetobacter baumannii 17978. Sci Rep 10 (1):1991. doi:10.1038/s41598-020-58522-5

37. Tipton KA, Rather PN (2017) An ompR-envZ Two-Component System Ortholog Regulates Phase Variation, Osmotic Tolerance, Motility, and Virulence in Acinetobacter baumannii Strain AB5075. J Bacteriol 199 (3). doi:10.1128/JB.00705-16

38. Tipton KA, Dimitrova D, Rather PN (2015) Phase-Variable Control of Multiple Phenotypes in Acinetobacter baumannii Strain AB5075. J Bacteriol 197 (15):2593-2599. doi:10.1128/JB.0018815

39. Giles SK, Stroeher UH, Eijkelkamp BA, Brown MH (2015) Identification of genes essential for pellicle formation in Acinetobacter baumannii. BMC Microbiol 15:116. doi:10.1186/s12866-0150440-6

40. Wilharm G, Skiebe E, Higgins PG, Poppel MT, Blaschke U, Leser S, Heider C, Heindorf M, Brauner P, Jackel U, Bohland K, Cuny C, Lopinska A, Kaminski P, Kasprzak M, Bochenski M, Ciebiera O, Tobolka M, Zolnierowicz KM, Siekiera J, Seifert H, Gagne S, Salcedo SP, Kaatz M, Layer F, Bender JK, Fuchs S, Semmler T, Pfeifer Y, Jerzak L (2017) Relatedness of wildlife and livestock avian isolates of the nosocomial pathogen Acinetobacter baumannii to lineages spread in hospitals worldwide. Environ Microbiol 19 (10):4349-4364. doi:10.1111/1462-2920.13931

41. Godeux AS, Lupo A, Haenni M, Guette-Marquet S, Wilharm G, Laaberki MH, Charpentier X (2018) Fluorescence-Based Detection of Natural Transformation in Drug-Resistant Acinetobacter baumannii. J Bacteriol 200 (19). doi:10.1128/JB.00181-18

42. Ahmad I, Karah N, Nadeem A, Wai SN, Uhlin BE (2019) Analysis of colony phase variation switch in Acinetobacter baumannii clinical isolates. PLoS One 14 (1):e0210082. doi:10.1371/journal.pone.0210082

43. Choi KH, Kumar A, Schweizer HP (2006) A 10-min method for preparation of highly electrocompetent Pseudomonas aeruginosa cells: application for DNA fragment transfer between chromosomes and plasmid transformation. J Microbiol Methods 64 (3):391-397. doi:10.1016/j.mimet.2005.06.001

44. Kentache T, Ben Abdelkrim A, Jouenne T, De E, Hardouin J (2017) Global Dynamic Proteome Study of a Pellicle-forming Acinetobacter baumannii Strain. Mol Cell Proteomics 16 (1):100-112. doi:10.1074/mcp.M116.061044

45. Nait Chabane Y, Marti S, Rihouey C, Alexandre S, Hardouin J, Lesouhaitier O, Vila J, Kaplan JB, Jouenne T, De E (2014) Characterisation of pellicles formed by Acinetobacter baumannii at the air-liquid interface. PLoS One 9 (10):e111660. doi:10.1371/journal.pone.0111660 
46. Kinsinger RF, Kearns DB, Hale M, Fall R (2005) Genetic requirements for potassium ion-dependent colony spreading in Bacillus subtilis. J Bacteriol 187 (24):8462-8469. doi:10.1128/JB.187.24.84628469.2005

47. Yan F, Yu Y, Gozzi K, Chen Y, Guo JH, Chai Y (2017) Genome-Wide Investigation of Biofilm Formation in Bacillus cereus. Appl Environ Microbiol 83 (13). doi:10.1128/AEM.00561-17

48. Okshevsky M, Louw MG, Lamela EO, Nilsson M, Tolker-Nielsen T, Meyer RL (2018) A transposon mutant library of Bacillus cereus ATCC 10987 reveals novel genes required for biofilm formation and implicates motility as an important factor for pellicle-biofilm formation. Microbiologyopen 7 (2):e00552. doi:10.1002/mbo3.552

49. Vilain S, Pretorius JM, Theron J, Brozel VS (2009) DNA as an adhesin: Bacillus cereus requires extracellular DNA to form biofilms. Appl Environ Microbiol 75 (9):2861-2868. doi:10.1128/AEM.01317-08

50. Zhang X, de Maat V, Guzman Prieto AM, Prajsnar TK, Bayjanov JR, de Been M, Rogers MRC, Bonten MJM, Mesnage S, Willems RJL, van Schaik W (2017) RNA-seq and Tn-seq reveal fitness determinants of vancomycin-resistant Enterococcus faecium during growth in human serum. BMC Genomics 18 (1):893. doi:10.1186/s12864-017-4299-9

51. Samant S, Lee H, Ghassemi M, Chen J, Cook JL, Mankin AS, Neyfakh AA (2008) Nucleotide biosynthesis is critical for growth of bacteria in human blood. PLoS Pathog 4 (2):e37. doi:10.1371/journal.ppat.0040037

52. Schwager S, Agnoli K, Kothe M, Feldmann F, Givskov M, Carlier A, Eberl L (2013) Identification of Burkholderia cenocepacia strain H111 virulence factors using nonmammalian infection hosts. Infect Immun 81 (1):143-153. doi:10.1128/IAI.00768-12

53. Wang N, Ozer EA, Mandel MJ, Hauser AR (2014) Genome-wide identification of Acinetobacter baumannii genes necessary for persistence in the lung. MBio 5 (3):e01163-01114. doi:10.1128/mBio.01163-14

54. Polissi A, Pontiggia A, Feger G, Altieri M, Mottl H, Ferrari L, Simon D (1998) Large-scale identification of virulence genes from Streptococcus pneumoniae. Infect Immun 66 (12):56205629

55. Jenkins A, Cote C, Twenhafel N, Merkel T, Bozue J, Welkos S (2011) Role of purine biosynthesis in Bacillus anthracis pathogenesis and virulence. Infect Immun 79 (1):153-166. doi:10.1128/IAI.00925-10

56. Fuller TE, Kennedy MJ, Lowery DE (2000) Identification of Pasteurella multocida virulence genes in a septicemic mouse model using signature-tagged mutagenesis. Microb Pathog 29 (1):25-38. doi:10.1006/mpat.2000.0365 
57. Yee R, Cui P, Shi W, Feng J, Zhang Y (2015) Genetic Screen Reveals the Role of Purine Metabolism in Staphylococcus aureus Persistence to Rifampicin. Antibiotics (Basel) 4 (4):627-642. doi:10.3390/antibiotics4040627

58. Charlier D, Nguyen Le Minh P, Roovers M (2018) Regulation of carbamoylphosphate synthesis in Escherichia coli: an amazing metabolite at the crossroad of arginine and pyrimidine biosynthesis. Amino Acids 50 (12):1647-1661. doi:10.1007/s00726-018-2654-z

59. Ueda A, Attila C, Whiteley M, Wood TK (2009) Uracil influences quorum sensing and biofilm formation in Pseudomonas aeruginosa and fluorouracil is an antagonist. Microb Biotechnol 2 (1):62-74. doi:10.1111/j.1751-7915.2008.00060.x

60. Garavaglia M, Rossi E, Landini P (2012) The pyrimidine nucleotide biosynthetic pathway modulates production of biofilm determinants in Escherichia coli. PLoS One 7 (2):e31252. doi:10.1371/journal.pone.0031252

61. Beaume M, Kohler T, Fontana T, Tognon M, Renzoni A, van Delden C (2015) Metabolic pathways of Pseudomonas aeruginosa involved in competition with respiratory bacterial pathogens. Front Microbiol 6:321. doi:10.3389/fmicb.2015.00321

62. Zhuo T, Rou W, Song X, Guo J, Fan X, Kamau GG, Zou H (2015) Molecular study on the carAB operon reveals that carB gene is required for swimming and biofilm formation in Xanthomonas citri subsp. citri. BMC Microbiol 15:225. doi:10.1186/s12866-015-0555-9

63. Kisselev LL, Justesen J, Wolfson AD, Frolova LY (1998) Diadenosine oligophosphates (Ap(n)A), a novel class of signalling molecules? FEBS Lett 427 (2):157-163. doi:10.1016/s00145793(98)00420-7

64. Bochner BR, Lee PC, Wilson SW, Cutler CW, Ames BN (1984) Appppa and Related Adenylylated Nucleotides Are Synthesized as a Consequence of Oxidation Stress. Cell 37 (1):225-232. doi:Doi 10.1016/0092-8674(84)90318-0

65. Linster CL, Van Schaftingen E, Hanson AD (2013) Metabolite damage and its repair or preemption. Nat Chem Biol 9 (2):72-80. doi:10.1038/nchembio.1141

66. Despotovic D, Brandis A, Savidor A, Levin Y, Fumagalli L, Tawfik DS (2017) Diadenosine tetraphosphate (Ap4A) - an E. coli alarmone or a damage metabolite? FEBS J 284 (14):21942215. doi:10.1111/febs.14113

67. Hudecek O, Benoni R, Reyes-Gutierrez PE, Culka M, Sanderova H, Hubalek M, Rulisek L, Cvacka J, Krasny L, Cahova H (2020) Dinucleoside polyphosphates act as 5'-RNA caps in bacteria. Nat Commun 11 (1):1052. doi:10.1038/s41467-020-14896-8 
68. Farr SB, Arnosti DN, Chamberlin MJ, Ames BN (1989) An apaH mutation causes AppppA to accumulate and affects motility and catabolite repression in Escherichia coli. Proc Natl Acad Sci U S A 86 (13):5010-5014. doi:10.1073/pnas.86.13.5010

69. Ismail TM, Hart CA, McLennan AG (2003) Regulation of dinucleoside polyphosphate pools by the YgdP and ApaH hydrolases is essential for the ability of Salmonella enterica serovar typhimurium to invade cultured mammalian cells. J Biol Chem 278 (35):32602-32607. doi:10.1074/jbc.M305994200

70. Ji X, Zou J, Peng H, Stolle AS, Xie R, Zhang H, Peng B, Mekalanos JJ, Zheng J (2019) Alarmone Ap4A is elevated by aminoglycoside antibiotics and enhances their bactericidal activity. Proc Natl Acad Sci U S A 116 (19):9578-9585. doi:10.1073/pnas.1822026116

71. Hansen S, Lewis K, Vulic M (2008) Role of global regulators and nucleotide metabolism in antibiotic tolerance in Escherichia coli. Antimicrob Agents Chemother 52 (8):2718-2726. doi:10.1128/AAC.00144-08

72. Monds RD, Newell PD, Wagner JC, Schwartzman JA, Lu W, Rabinowitz JD, O'Toole GA (2010) Diadenosine tetraphosphate (Ap4A) metabolism impacts biofilm formation by Pseudomonas fluorescens via modulation of c-di-GMP-dependent pathways. J Bacteriol 192 (12):3011-3023. doi:10.1128/JB.01571-09

73. Goerlich O, Foeckler R, Holler E (1982) Mechanism of synthesis of adenosine( (5')tetraphospho(5')adenosine (AppppA) by aminoacyl-tRNA synthetases. Eur J Biochem 126 (1):135-142. doi:10.1111/j.1432-1033.1982.tb06757.x

74. Fraga H, Fontes R (2011) Enzymatic synthesis of mono and dinucleoside polyphosphates. Biochim Biophys Acta 1810 (12):1195-1204. doi:10.1016/j.bbagen.2011.09.010

75. Petersen LM, Tisa LS (2014) Molecular characterization of protease activity in Serratia sp. strain SCBI and its importance in cytotoxicity and virulence. J Bacteriol 196 (22):3923-3936. doi:10.1128/JB.01908-14

76. Kinscherf TG, Willis DK (2002) Global regulation by gidA in Pseudomonas syringae. J Bacteriol 184 (8):2281-2286. doi:10.1128/jb.184.8.2281-2286.2002

77. Shippy DC, Fadl AA (2015) RNA modification enzymes encoded by the gid operon: Implications in biology and virulence of bacteria. Microb Pathog 89:100-107. doi:10.1016/j.micpath.2015.09.008

78. Shin JH, Lee HW, Kim SM, Kim J (2009) Proteomic analysis of Acinetobacter baumannii in biofilm and planktonic growth mode. J Microbiol 47 (6):728-735. doi:10.1007/s12275-009-0158-y 
79. Zhang W, Zhao Z, Zhang B, Wu XG, Ren ZG, Zhang LQ (2014) Posttranscriptional regulation of 2,4diacetylphloroglucinol production by GidA and TrmE in Pseudomonas fluorescens 2P24. Appl Environ Microbiol 80 (13):3972-3981. doi:10.1128/AEM.00455-14

80. Li D, Shibata Y, Takeshita T, Yamashita Y (2014) A novel gene involved in the survival of Streptococcus mutans under stress conditions. Appl Environ Microbiol 80 (1):97-103. doi:10.1128/AEM.02549-13

81. Yi H, Lee H, Cho KH, Kim HS (2018) Mutations in MetG (methionyl-tRNA synthetase) and TrmD [tRNA (guanine-N1)-methyltransferase] conferring meropenem tolerance in Burkholderia thailandensis. J Antimicrob Chemother 73 (2):332-338. doi:10.1093/jac/dkx378

82. Brauner A, Fridman O, Gefen O, Balaban NQ (2016) Distinguishing between resistance, tolerance and persistence to antibiotic treatment. Nat Rev Microbiol 14 (5):320-330. doi:10.1038/nrmicro.2016.34

83. Fridman O, Goldberg A, Ronin I, Shoresh N, Balaban NQ (2014) Optimization of lag time underlies antibiotic tolerance in evolved bacterial populations. Nature 513 (7518):418-421. doi:10.1038/nature13469

84. Bolt EL, Jenkins T, Russo VM, Ahmed S, Cavey J, Cass SD (2015) Identification of Escherichia coli ygaQ and rpmG as novel mitomycin C resistance factors implicated in DNA repair. Biosci Rep 36 (1):e00290. doi:10.1042/BSR20150249

85. Smirnova GV, Oktyabrsky ON (2005) Glutathione in bacteria. Biochemistry (Mosc) 70 (11):11991211. doi:10.1007/s10541-005-0248-3

86. Jamieson DJ (1998) Oxidative stress responses of the yeast Saccharomyces cerevisiae. Yeast 14 (16):1511-1527. doi:10.1002/(SICI)1097-0061(199812)14:16<1511::AID-YEA356>3.0.CO;2-S

87. Van Laar TA, Esani S, Birges TJ, Hazen B, Thomas JM, Rawat M (2018) Pseudomonas aeruginosa gshA Mutant Is Defective in Biofilm Formation, Swarming, and Pyocyanin Production. mSphere 3 (2). doi:10.1128/mSphere.00155-18

88. Wongsaroj L, Saninjuk K, Romsang A, Duang-Nkern J, Trinachartvanit W, Vattanaviboon P, Mongkolsuk S (2018) Pseudomonas aeruginosa glutathione biosynthesis genes play multiple roles in stress protection, bacterial virulence and biofilm formation. PLoS One 13 (10):e0205815. doi:10.1371/journal.pone.0205815

89. Gomez MJ, Neyfakh AA (2006) Genes involved in intrinsic antibiotic resistance of Acinetobacter baylyi. Antimicrob Agents Chemother 50 (11):3562-3567. doi:10.1128/AAC.00579-06

90. Feinbaum RL, Urbach JM, Liberati NT, Djonovic S, Adonizio A, Carvunis AR, Ausubel FM (2012) Genome-wide identification of Pseudomonas aeruginosa virulence-related genes using a 
Caenorhabditis elegans infection model. PLoS Pathog 8 (7):e1002813. doi:10.1371/journal.ppat.1002813

91. Song M, Husain M, Jones-Carson J, Liu L, Henard CA, Vazquez-Torres A (2013) Low-molecularweight thiol-dependent antioxidant and antinitrosative defences in Salmonella pathogenesis. Mol Microbiol 87 (3):609-622. doi:10.1111/mmi.12119

92. Westley J (1981) Thiosulfate: cyanide sulfurtransferase (rhodanese). Methods Enzymol 77:285291. doi:10.1016/s0076-6879(81)77039-3

93. Donadio S, Shafiee A, Hutchinson CR (1990) Disruption of a rhodaneselike gene results in cysteine auxotrophy in Saccharopolyspora erythraea. J Bacteriol 172 (1):350-360. doi:10.1128/jb.172.1.350-360.1990

94. Pagani S, Bonomi F, Cerletti P (1984) Enzymic synthesis of the iron-sulfur cluster of spinach ferredoxin. Eur J Biochem 142 (2):361-366. doi:10.1111/j.1432-1033.1984.tb08295.x

95. Bonomi F, Pagani S, Kurtz DM, Jr. (1985) Enzymic synthesis of the 4Fe-4S clusters of Clostridium pasteurianum ferredoxin. Eur J Biochem 148 (1):67-73. doi:10.1111/j.1432-1033.1985.tb08808.x

96. Navidifar T, Amin M, Rashno M (2019) Effects of sub-inhibitory concentrations of meropenem and tigecycline on the expression of genes regulating pili, efflux pumps and virulence factors involved in biofilm formation by Acinetobacter baumannii. Infect Drug Resist 12:1099-1111. doi:10.2147/IDR.S199993

97. Yang CH, Su PW, Moi SH, Chuang LY (2019) Biofilm Formation in Acinetobacter Baumannii: Genotype-Phenotype Correlation. Molecules 24 (10). doi:10.3390/molecules24101849

98. Gaddy JA, Tomaras AP, Actis LA (2009) The Acinetobacter baumannii 19606 OmpA protein plays a role in biofilm formation on abiotic surfaces and in the interaction of this pathogen with eukaryotic cells. Infect Immun 77 (8):3150-3160. doi:10.1128/IAI.00096-09

99. Confer AW, Ayalew S (2013) The OmpA family of proteins: roles in bacterial pathogenesis and immunity. Vet Microbiol 163 (3-4):207-222. doi:10.1016/j.vetmic.2012.08.019

100. Skerniskyte J, Karazijaite E, Deschamps J, Krasauskas R, Briandet R, Suziedeliene E (2019) The Mutation of Conservative Asp268 Residue in the Peptidoglycan-Associated Domain of the OmpA Protein Affects Multiple Acinetobacter baumannii Virulence Characteristics. Molecules 24 (10). doi:10.3390/molecules24101972

101. Insua JL, Llobet E, Moranta D, Perez-Gutierrez C, Tomas A, Garmendia J, Bengoechea JA (2013) Modeling Klebsiella pneumoniae pathogenesis by infection of the wax moth Galleria mellonella. Infect Immun 81 (10):3552-3565. doi:10.1128/IAI.00391-13

102. Justice SS, Hunstad DA, Cegelski L, Hultgren SJ (2008) Morphological plasticity as a bacterial survival strategy. Nat Rev Microbiol 6 (2):162-168. doi:10.1038/nrmicro1820 
103. Robertson GT, Case ED, Dobbs N, Ingle C, Balaban M, Celli J, Norgard MV (2014) FTT0831c/FTL_0325 contributes to Francisella tularensis cell division, maintenance of cell shape, and structural integrity. Infect Immun 82 (7):2935-2948. doi:10.1128/IAI.00102-14

104. Egan AJF (2018) Bacterial outer membrane constriction. Mol Microbiol 107 (6):676-687. doi:10.1111/mmi.13908

105. Kim SW, Choi CH, Moon DC, Jin JS, Lee JH, Shin JH, Kim JM, Lee YC, Seol SY, Cho DT, Lee JC (2009) Serum resistance of Acinetobacter baumannii through the binding of factor $\mathrm{H}$ to outer membrane proteins. FEMS Microbiol Lett 301 (2):224-231. doi:10.1111/j.1574$6968.2009 .01820 . x$

106. Choi CH, Lee JS, Lee YC, Park TI, Lee JC (2008) Acinetobacter baumannii invades epithelial cells and outer membrane protein A mediates interactions with epithelial cells. BMC Microbiol 8:216. doi:10.1186/1471-2180-8-216

107. Kwon HI, Kim S, Oh MH, Na SH, Kim YJ, Jeon YH, Lee JC (2017) Outer membrane protein A contributes to antimicrobial resistance of Acinetobacter baumannii through the OmpA-like domain. J Antimicrob Chemother 72 (11):3012-3015. doi:10.1093/jac/dkx257

108. Rumbo-Feal S, Perez A, Ramelot TA, Alvarez-Fraga L, Vallejo JA, Beceiro A, Ohneck EJ, Arivett BA, Merino M, Fiester SE, Kennedy MA, Actis LA, Bou G, Poza M (2017) Contribution of the A. baumannii A1S_0114 Gene to the Interaction with Eukaryotic Cells and Virulence. Front Cell Infect Microbiol 7:108. doi:10.3389/fcimb.2017.00108

109. Rumbo-Feal S, Gomez MJ, Gayoso C, Alvarez-Fraga L, Cabral MP, Aransay AM, RodriguezEzpeleta N, Fullaondo A, Valle J, Tomas M, Bou G, Poza M (2013) Whole transcriptome analysis of Acinetobacter baumannii assessed by RNA-sequencing reveals different mRNA expression profiles in biofilm compared to planktonic cells. PLoS One 8 (8):e72968. doi:10.1371/journal.pone.0072968

110. Chang KC, Kuo HY, Tang CY, Chang CW, Lu CW, Liu CC, Lin HR, Chen KH, Liou ML (2014) Transcriptome profiling in imipenem-selected Acinetobacter baumannii. BMC Genomics 15:815. doi:10.1186/1471-2164-15-815

111. Gebhardt MJ, Gallagher LA, Jacobson RK, Usacheva EA, Peterson LR, Zurawski DV, Shuman HA (2015) Joint Transcriptional Control of Virulence and Resistance to Antibiotic and Environmental Stress in Acinetobacter baumannii. MBio 6 (6):e01660-01615. doi:10.1128/mBio.01660-15 112. Blaschke U, Suwono B, Zafari S, Ebersberger I, Skiebe E, Jeffries CM, Svergun DI, Wilharm G (2018) Recombinant production of A1S_0222 from Acinetobacter baumannii ATCC 17978 and confirmation of its DNA-(adenine N6)-methyltransferase activity. Protein Expr Purif 151:78-85. doi:10.1016/j.pep.2018.06.009 
113. Roberts RJ, Vincze T, Posfai J, Macelis D (2015) REBASE-a database for DNA restriction and modification: enzymes, genes and genomes. Nucleic Acids Research 43 (D1):D298-D299. doi:10.1093/nar/gku1046

114. Wion D, Casadesus J (2006) N6-methyl-adenine: an epigenetic signal for DNA-protein interactions. Nat Rev Microbiol 4 (3):183-192. doi:10.1038/nrmicro1350

115. Adhikari S, Curtis PD (2016) DNA methyltransferases and epigenetic regulation in bacteria. FEMS Microbiol Rev 40 (5):575-591. doi:10.1093/femsre/fuw023

116. Marinus MG, Morris NR (1973) Isolation of deoxyribonucleic acid methylase mutants of Escherichia coli K-12. J Bacteriol 114 (3):1143-1150

117. Collier J (2009) Epigenetic regulation of the bacterial cell cycle. Curr Opin Microbiol 12 (6):722729. doi:10.1016/j.mib.2009.08.005

118. Salzer R, Kern T, Joos F, Averhoff B (2016) The Thermus thermophilus comEA/comEC operon is associated with DNA binding and regulation of the DNA translocator and type IV pili. Environ Microbiol 18 (1):65-74. doi:10.1111/1462-2920.12820

119. Rabinovich L, Sigal N, Borovok I, Nir-Paz R, Herskovits AA (2012) Prophage excision activates Listeria competence genes that promote phagosomal escape and virulence. Cell 150 (4):792802. doi:10.1016/j.cell.2012.06.036

120. Yoshida A, Kuramitsu HK (2002) Multiple Streptococcus mutans Genes Are Involved in Biofilm Formation. Appl Environ Microbiol 68 (12):6283-6291. doi:10.1128/aem.68.12.6283-6291.2002

121. Lees-Miller RG, Iwashkiw JA, Scott NE, Seper A, Vinogradov E, Schild S, Feldman MF (2013) A common pathway for O-linked protein-glycosylation and synthesis of capsule in Acinetobacter baumannii. Mol Microbiol 89 (5):816-830. doi:10.1111/mmi.12300

122. Russo TA, Luke NR, Beanan JM, Olson R, Sauberan SL, MacDonald U, Schultz LW, Umland TC, Campagnari AA (2010) The K1 capsular polysaccharide of Acinetobacter baumannii strain 3070294 is a major virulence factor. Infect Immun 78 (9):3993-4000. doi:10.1128/IAI.00366-10

123. Schaper S, Wendt H, Bamberger J, Sieber V, Schmid J, Becker A (2019) A Bifunctional UDP-Sugar 4-Epimerase Supports Biosynthesis of Multiple Cell Surface Polysaccharides in Sinorhizobium meliloti. J Bacteriol 201 (10). doi:10.1128/JB.00801-18

124. Nesper J, Lauriano CM, Klose KE, Kapfhammer D, Kraiss A, Reidl J (2001) Characterization of Vibrio cholerae $\mathrm{O} 1 \mathrm{EI}$ tor galU and galE mutants: influence on lipopolysaccharide structure, colonization, and biofilm formation. Infect Immun 69 (1):435-445. doi:10.1128/IAI.69.1.435445.2001 
125. Chai Y, Beauregard PB, Vlamakis H, Losick R, Kolter R (2012) Galactose metabolism plays a crucial role in biofilm formation by Bacillus subtilis. MBio 3 (4):e00184-00112. doi:10.1128/mBio.00184-12

126. Niou YK, Wu WL, Lin LC, Yu MS, Shu HY, Yang HH, Lin GH (2009) Role of galE on biofilm formation by Thermus spp. Biochem Biophys Res Commun 390 (2):313-318. doi:10.1016/j.bbrc.2009.09.120

127. Zou Y, Feng S, Xu C, Zhang B, Zhou S, Zhang L, He X, Li J, Yang Z, Liao M (2013) The role of galU and galE of Haemophilus parasuis SC096 in serum resistance and biofilm formation. Vet Microbiol 162 (1):278-284. doi:10.1016/j.vetmic.2012.08.006

128. Nakao R, Senpuku H, Watanabe $H$ (2006) Porphyromonas gingivalis galE is involved in lipopolysaccharide O-antigen synthesis and biofilm formation. Infect Immun 74 (11):6145-6153. doi:10.1128/IAI.00261-06

129. Cabral MP, Soares NC, Aranda J, Parreira JR, Rumbo C, Poza M, Valle J, Calamia V, Lasa I, Bou G (2011) Proteomic and functional analyses reveal a unique lifestyle for Acinetobacter baumannii biofilms and a key role for histidine metabolism. J Proteome Res 10 (8):3399-3417. doi:10.1021/pr101299j

130. Chateau A, Lunderberg JM, Oh SY, Abshire T, Friedlander A, Quinn CP, Missiakas DM, Schneewind O (2018) Galactosylation of the Secondary Cell Wall Polysaccharide of Bacillus anthracis and Its Contribution to Anthrax Pathogenesis. J Bacteriol 200 (5). doi:10.1128/JB.00562-17

131. Zeng Y, He Y, Wang KY, Wang J, Zeng YK, Chen YX, Chen D, Geng Y, OuYang P (2016) cpsJ gene of Streptococcus iniae is involved in capsular polysaccharide synthesis and virulence. Antonie Van Leeuwenhoek 109 (11):1483-1492. doi:10.1007/s10482-016-0750-1

132. Remy E, Meyer M, Blaise F, Simon UK, Kuhn D, Balesdent MH, Rouxel T (2009) A key enzyme of the Leloir pathway is involved in pathogenicity of Leptosphaeria maculans toward oilseed rape. Mol Plant Microbe Interact 22 (6):725-736. doi:10.1094/MPMI-22-6-0725

133. Anton DN (1995) Resistance to mecillinam produced by the co-operative action of mutations affecting lipopolysaccharide, spoT, and cya or crp genes of Salmonella typhimurium. Mol Microbiol 16 (3):587-595. doi:10.1111/j.1365-2958.1995.tb02421.x

134. Hickman FW, Rhoden DL, Esaias AO, Baron LS, Brenner DJ, Farmer JJ, 3rd (1982) Evaluation of two Salmonella typhi strains with reduced virulence for use in teaching and proficiency testing. J Clin Microbiol 15 (6):1085-1091 
135. Carlson-Banning KM, Chou A, Liu Z, Hamill RJ, Song Y, Zechiedrich L (2013) Toward repurposing ciclopirox as an antibiotic against drug-resistant Acinetobacter baumannii, Escherichia coli, and Klebsiella pneumoniae. PLoS One 8 (7):e69646. doi:10.1371/journal.pone.0069646

136. Dey S, Lane JM, Lee RE, Rubin EJ, Sacchettini JC (2010) Structural characterization of the Mycobacterium tuberculosis biotin biosynthesis enzymes 7,8-diaminopelargonic acid synthase and dethiobiotin synthetase. Biochemistry 49 (31):6746-6760. doi:10.1021/bi902097j

137. Salaemae W, Azhar A, Booker GW, Polyak SW (2011) Biotin biosynthesis in Mycobacterium tuberculosis: physiology, biochemistry and molecular intervention. Protein Cell 2 (9):691-695. doi:10.1007/s13238-011-1100-8

138. Said HM (2009) Cell and molecular aspects of human intestinal biotin absorption. J Nutr 139 (1):158-162. doi:10.3945/jn.108.092023

139. Woong Park S, Klotzsche M, Wilson DJ, Boshoff HI, Eoh H, Manjunatha U, Blumenthal A, Rhee K, Barry CE, 3rd, Aldrich CC, Ehrt S, Schnappinger D (2011) Evaluating the sensitivity of Mycobacterium tuberculosis to biotin deprivation using regulated gene expression. PLoS Pathog 7 (9):e1002264. doi:10.1371/journal.ppat.1002264

140. Mu X, Wang N, Li X, Shi K, Zhou Z, Yu Y, Hua X (2016) The Effect of Colistin Resistance-Associated Mutations on the Fitness of Acinetobacter baumannii. Front Microbiol 7:1715. doi:10.3389/fmicb.2016.01715

141. Shirai $H$, Mizuguchi K (2003) Prediction of the structure and function of AstA and AstB, the first two enzymes of the arginine succinyltransferase pathway of arginine catabolism. FEBS Lett 555 (3):505-510. doi:10.1016/s0014-5793(03)01314-0

142. Peleg AY, Jara S, Monga D, Eliopoulos GM, Moellering RC, Jr., Mylonakis E (2009) Galleria mellonella as a model system to study Acinetobacter baumannii pathogenesis and therapeutics. Antimicrob Agents Chemother 53 (6):2605-2609. doi:10.1128/AAC.01533-08

143. Jacobs AC, Thompson MG, Black CC, Kessler JL, Clark LP, McQueary CN, Gancz HY, Corey BW, Moon JK, Si Y, Owen MT, Hallock JD, Kwak YI, Summers A, Li CZ, Rasko DA, Penwell WF, Honnold CL, Wise MC, Waterman PE, Lesho EP, Stewart RL, Actis LA, Palys TJ, Craft DW, Zurawski DV (2014) AB5075, a Highly Virulent Isolate of Acinetobacter baumannii, as a Model Strain for the Evaluation of Pathogenesis and Antimicrobial Treatments. MBio 5 (3):e01076-01014. doi:10.1128/mBio.01076-14

144. Harms K, Lunnan A, Hulter N, Mourier T, Vinner L, Andam CP, Marttinen P, Fridholm H, Hansen AJ, Hanage WP, Nielsen KM, Willerslev E, Johnsen PJ (2016) Substitutions of short heterologous DNA segments of intragenomic or extragenomic origins produce clustered genomic polymorphisms. Proc Natl Acad Sci U S A 113 (52):15066-15071. doi:10.1073/pnas.1615819114 

made available under aCC-BY 4.0 International license.

1279 145. Domingues S, Harms K, Fricke WF, Johnsen PJ, da Silva GJ, Nielsen KM (2012) Natural transformation facilitates transfer of transposons, integrons and gene cassettes between bacterial species. PLoS Pathog 8 (8):e1002837. doi:10.1371/journal.ppat.1002837 
Table 1. Summary of experimental results on genes involved in surface-associated motility in A. baumannii ATCC 17978

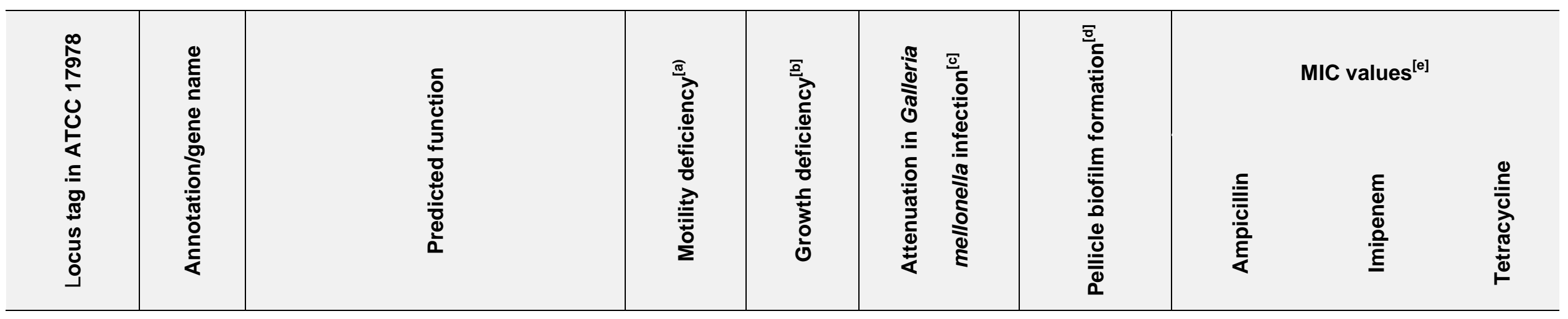

Purine/pyrimidine/folate biosynthesis

\begin{tabular}{|c|c|c|c|c|c|c|c|c|c|}
\hline & & phosphoribosylaminoimidazolecarbo & & & & & & & \\
\hline A1S_2187 & purH & $\begin{array}{l}\text { xamide formyltransferase (purine } \\
\text { synthesis) }\end{array}$ & + & $\mathrm{Y}$ & N.s. & $\uparrow^{\uparrow^{* *}}$ & N.s. & N.s. & N.s. \\
\hline A1S_2251 & purF & $\begin{array}{l}\text { amidophosphoribosyltransferase } \\
\text { (purine synthesis) }\end{array}$ & ++ & $\mathrm{Y}$ & N.s. & N.s. & $\mathrm{R}^{\star \star \star *}$ & N.s. & $\mathrm{R}$ * \\
\hline A1S_2605 & purM & $\begin{array}{l}\text { phosphoribosylaminoimidazole } \\
\text { synthetase (purine synthesis) }\end{array}$ & +++ & $\mathrm{Y}$ & * & $\uparrow^{*}$ & $\mathrm{R}^{\star \star \star}$ & N.S. & $\mathrm{S}$ * \\
\hline A1S_2964 & purE & phosphoribosylaminoimidazole & +++ & $\mathrm{Y}$ & N.s. & $\uparrow^{* * *}$ & $\mathrm{R}^{\star \star \star}$ & $S^{* \star}$ & $\mathrm{S}$ * \\
\hline
\end{tabular}




\begin{tabular}{|c|c|c|c|c|c|c|c|c|c|}
\hline & & $\begin{array}{c}\text { carboxylase mutase subunit (purine } \\
\text { synthesis) }\end{array}$ & & & & & & & \\
\hline A1S_1566 & & $\begin{array}{l}\text { 6-pyruvoyl-tetrahydropterin synthase } \\
\text { (folate biosynthesis) }\end{array}$ & +++ & $\mathrm{Y}$ & $\star \star$ & $\downarrow^{* * * *}$ & 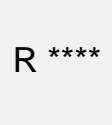 & N.s. & N.S. \\
\hline A1S_2687 & carB & subunit (pyrimidine synthesis) & ++ & Y & 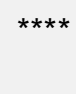 & $\downarrow^{* * * *}$ & N.S. & $S^{\star * \star *}$ & $S$ ** \\
\hline
\end{tabular}

Alarmones/ stress metabolism

\begin{tabular}{|c|c|c|c|c|c|c|c|c|}
\hline A1S_0414 & Ap5A pyrophosphatase & ++ & $\mathrm{Y}$ & * & $\downarrow^{* * * *}$ & $\mathrm{R} \star \star \star \star \star$ & N.s. & N.S. \\
\hline A1S_1624 & Ap4A hydrolase & ++ & $\mathrm{Y}$ & N.S. & N.S. & N.s. & $S * \star \star$ & N.S. \\
\hline
\end{tabular}

RNA modification/ regulation

\begin{tabular}{|c|c|c|c|c|c|c|c|c|c|}
\hline A1S_0447 & rpmG & 50S ribosomal protein L33 & +++ & $\mathrm{Y}$ & N.s. & N.s. & N.s. & $S$ * & $S * *$ \\
\hline A1S_0778 & metG & methionyl-tRNA synthetase & +++ & $Y$ & $\star \star \star \star ~$ & $\downarrow^{* * * *}$ & N.s. & N.s. & $S * \star *$ \\
\hline A1S_2182 & gidA & $\begin{array}{l}\text { Glucose-inhibited division protein } A \text {, } \\
\text { FAD-binding protein }\end{array}$ & ++ & $Y$ & N.s. & $\downarrow^{* * * *}$ & $\mathrm{R}$ * & N.s. & N.s. \\
\hline
\end{tabular}


Oxidative stress

\begin{tabular}{|c|c|c|c|c|c|c|c|c|c|}
\hline A1S_0530 & & $\begin{array}{c}\text { rhodanese domain-containing } \\
\text { protein, sulfurtransferase }\end{array}$ & ++ & $\mathrm{N}$ & N.s. & $\uparrow * * * *$ & N.s. & N.s. & N.S. \\
\hline A1S_3366 & $g \operatorname{sh} A$ & gamma-glutamate-cysteine ligase & ++ & $Y$ & * & N.s. & $\mathrm{R} * \star *$ & N.s. & N.s. \\
\hline
\end{tabular}

Outer membrane proteins

\begin{tabular}{|c|c|c|c|c|c|c|c|c|c|}
\hline A1S_1970 & & $\begin{array}{l}\text { outer membrane protein (Omp85 } \\
\text { family) }\end{array}$ & ++ & $\mathrm{Y}$ & $\star \star$ & $\downarrow^{* *}$ & $\mathrm{R} * \star \star \star$ & $S^{*}$ & N.s. \\
\hline A1S_2840 & ompA & outer membrane protein & ++ & $\mathrm{N}$ & 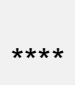 & $\downarrow^{* * * *}$ & N.s. & $\mathrm{R} * \star \star$ & $S$ * \\
\hline A1S_3297 & & putative outer membrane protein & + & $\mathrm{Y}$ & ** & $\uparrow^{* *}$ & $\mathrm{R} * \star \star$ & $\mathrm{R}$ * & N.S. \\
\hline
\end{tabular}

1,3-diaminopropane biosynthesis

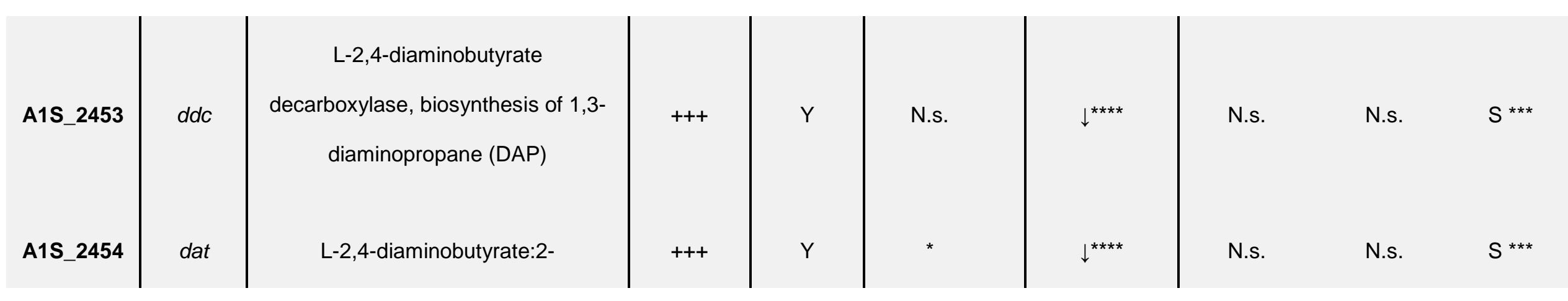



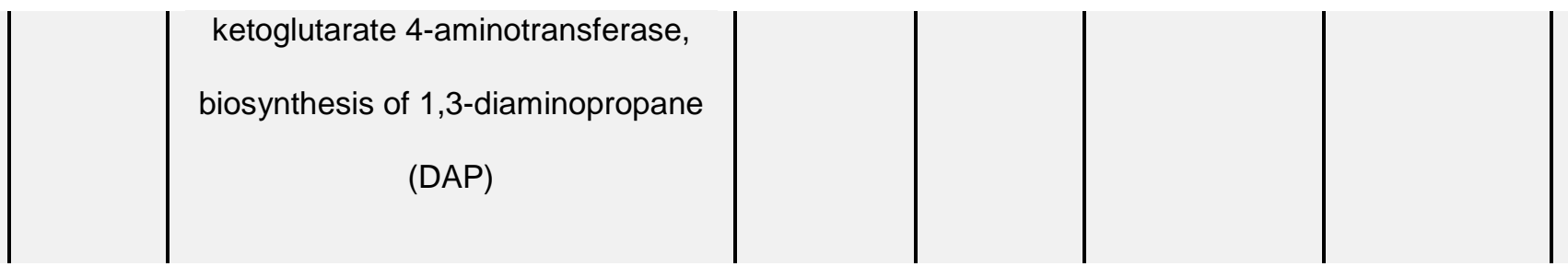

Lipopeptide synthesis/export

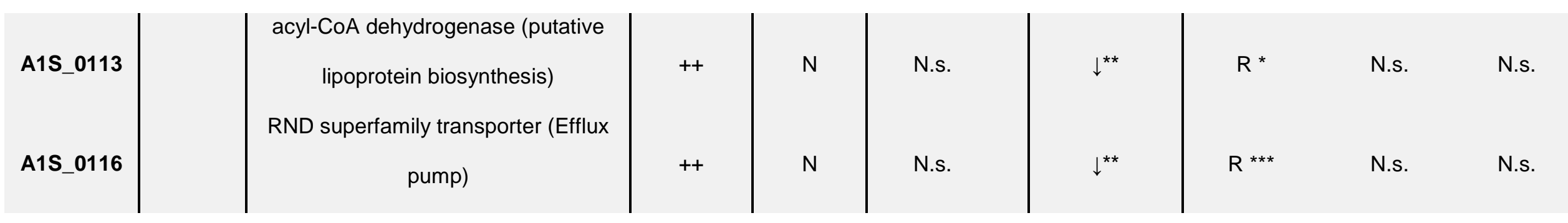

DNA modification/repair/uptake

\begin{tabular}{|c|c|c|c|c|c|c|c|c|c|}
\hline A1S_0222 & aamA & & ++ & $\mathrm{Y}$ & $\star \star \star *$ & $\downarrow^{\star * * *}$ & N.s. & $\mathrm{S} * \star \star$ & $\mathrm{S} * *$ \\
\hline A1S_2334 & sahH & $\begin{array}{c}\text { S-adenosyl-L-homocysteine } \\
\text { hydrolase }\end{array}$ & +++ & $\mathrm{Y}$ & * & N.s. & $\mathrm{R} * \star \star$ & N.s. & N.S. \\
\hline A1S_2587 & ruvA & holliday junction helicase subunit $A$ & ++ & $\mathrm{Y}$ & N.s. & $\downarrow^{* * * *}$ & $\mathrm{R} * * *$ & N.s. & $\mathrm{S} * *$ \\
\hline A1S_2610 & comEC & competence factor & ++ & $\mathrm{N}$ & $\star \star *$ & N.s. & N.s. & N.s. & N.S. \\
\hline
\end{tabular}


Others

\begin{tabular}{|c|c|c|c|c|c|c|c|c|c|}
\hline A1S_0065 & gale & $\begin{array}{l}\text { UDP-glucose 4-epimerase, } \\
\text { Lipopolysaccharide biosynthesis }\end{array}$ & ++ & $\mathrm{N}$ & 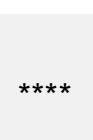 & $\uparrow^{\uparrow * \star \star *}$ & $\mathrm{R} * \star \star$ & N.s. & $\mathrm{R}^{*}$ \\
\hline A1S_0806 & & $\begin{array}{l}\text { adenosylmethionine-8-amino-7- } \\
\text { oxononanoate aminotransferase }\end{array}$ & +++ & $\mathrm{Y}$ & N.s. & $\uparrow^{\star * * *}$ & $\mathrm{R} * \star \star$ & $\mathrm{R}^{\star \star \star \star *}$ & N.S. \\
\hline A1S_1055 & & soluble lytic murein transglycosylase & ++ & $\mathrm{N}$ & ** & $\uparrow^{* *}$ & N.s. & N.s. & $\mathrm{S}^{*}$ \\
\hline A1S_2761 & $p r p F$ & 2-methylaconitate isomerase & +++ & $\mathrm{Y}$ & N.s. & $\downarrow^{\star * * *}$ & $\mathrm{R}$ * & N.s. & $S$ ** \\
\hline A1S_3026 & & $\begin{array}{l}\text { Hyp. Secreted Ribonuclease T2 } \\
\text { (predicted secretion signal) }\end{array}$ & ++ & $\mathrm{N}$ & N.s. & N.s. & $\mathrm{R}^{* \star \star *}$ & $\mathrm{R}^{* * *}$ & N.S. \\
\hline A1S_3129 & astB & succinylarginine dihydrolase & +++ & $\mathrm{Y}$ & N.s. & $\downarrow^{\star * * *}$ & $\mathrm{R} * \star *$ & N.s. & $S$ ** \\
\hline
\end{tabular}

$5 \quad{ }^{[b]}$ Comparison of bacterial growth curves. Y, growth deficiency compared to WT was observed; N, no growth deficiency was observed

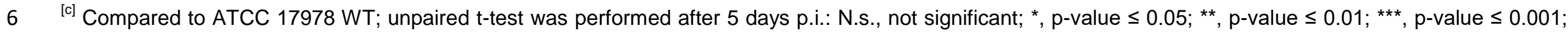

$7 \quad * * * *, p$-value $\leq 0.0001$ 
${ }^{\text {[d] }}$ Compared to ATCC 17978 WT; unpaired t-test was performed: N.S., not significant; ${ }^{*}, p$-value $\leq 0.05 ;{ }^{* *}, p$-value $\leq 0.01 ;{ }^{* * *}, p$-value $\leq 0.001 ;{ }^{* * * *}, p$-value $\leq$ $90.0001 ; \uparrow$, more than ATCC 17978 WT; $\downarrow$, less than ATCC 17978 WT

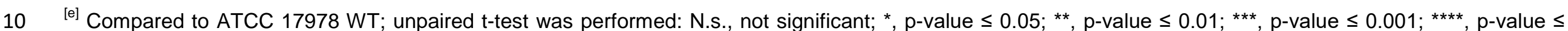
$11 \quad 0.0001 ; \mathrm{R}$, resistant; $\mathrm{S}$, susceptible 
Table 2. Summary of experimental results on genes involved in surface-associated motility in A. baumannii 29D2. A dark grey background indicates concordance to results obtained for strain ATCC 17978

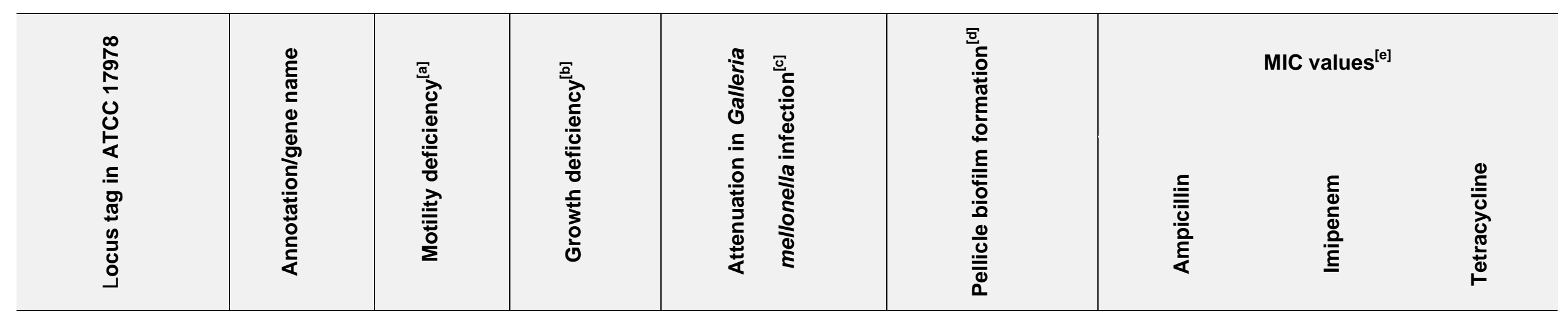

Purine/pyrimidine/folate biosynthesis

\begin{tabular}{|c|c|c|c|c|c|c|c|c|}
\hline A1S_2251 & purF & ++ & $\mathrm{Y}$ & N.s. & N.s. & $S^{* *}$ & $S^{*}$ & N.s. \\
\hline A1S_2605 & purM & + & $Y$ & N.s. & N.s. & $S^{*}$ & N.s. & N.s. \\
\hline A1S_1566 & & + & $\mathrm{Y}$ & 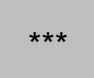 & N.s. & $S^{*}$ & N.s. & $S^{*}$ \\
\hline A1S_2687 & carB & + & Y & $\star \star \star \star *$ & $\downarrow^{* *}$ & $S^{* *}$ & $S$ ** & N.s. \\
\hline
\end{tabular}


Alarmones/stress metabolism

A1S_0414

RNA modification/ regulation $\operatorname{gid} A$

A1S_2182 gidA

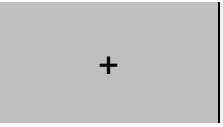

N

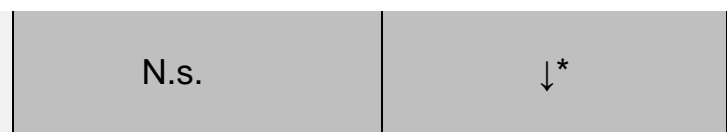

$\mathrm{S}$ *

N.s.

N.S.

Oxidative stress

$$
\text { (1) } 22 a 6
$$

A1S_3366
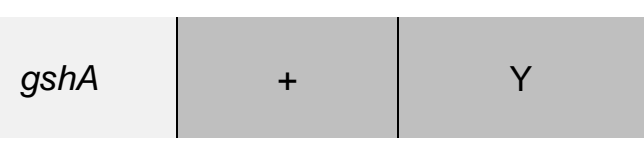

N.S.

\begin{tabular}{|l|l|} 
N.s. & $\downarrow^{* *}$ \\
$\star \star * \star *$ & N.S.
\end{tabular}

Outer membrane proteins
N.s.

N.S.

$S$ *

$S$ **

N.S.
N.S.

N.S.

N.s.

\begin{tabular}{l|l|l|l} 
A1S_1970 & + & $\mathrm{N}$ \\
A1S_2840 & ompA & + & $\mathrm{Y}$
\end{tabular}

1,3-diaminopropane biosynthesis

\begin{tabular}{l|l|l|l|} 
A1S_2453 & $d d c$ & ++ & $\mathrm{Y}$ \\
A1S_2454 & dat & + & $\mathrm{Y}$
\end{tabular}

N.s.

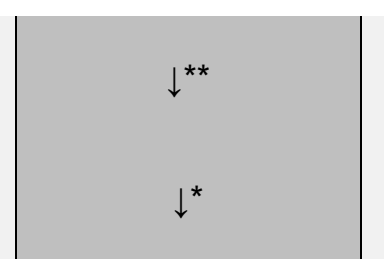


Lipopeptide synthesis/export

A1S_0116

DNA modification/repair/uptake

\begin{tabular}{l|l|l} 
A1S_0222 & aamA & + \\
A1S_2610 & comEC & +
\end{tabular}

Others

\begin{tabular}{|c|c|c|c|c|c|c|c|c|}
\hline A1S_0065 & gale & ++ & $\mathrm{Y}$ & 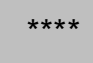 & $\uparrow^{*}$ & $S$ * & N.s. & N.s. \\
\hline A1S_0806 & & + & $\mathrm{N}$ & N.s. & N.s. & $S^{*}$ & $S^{\star \star \star \star *}$ & N.s. \\
\hline A1S_1055 & & + & $\mathrm{N}$ & $\star \star$ & N.s. & N.s. & $S^{*}$ & N.s. \\
\hline A1S_2761 & $p r p F$ & + & $\mathrm{Y}$ & ** & N.s. & $S$ * & $S$ * & $S$ * \\
\hline A1S_3026 & & + & $\mathrm{N}$ & 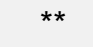 & $\downarrow^{*}$ & $\mathrm{R}$ * & $\mathrm{R}^{* \star *}$ & N.s. \\
\hline
\end{tabular}

[a] Compared to 29D2 wild type strain (WT); diameter of the spreading zone was measured: '+++', 0-3 mm; '++', <3-6 mm; '+', <6 mm

${ }^{[b]}$ Comparison of bacterial growth curves. Y, growth deficiency compared to WT was observed; N, no growth deficiency was observed 


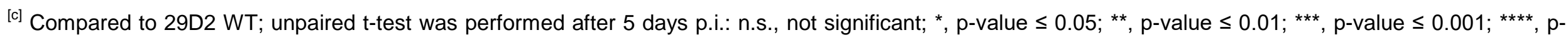
value $\leq 0.0001$

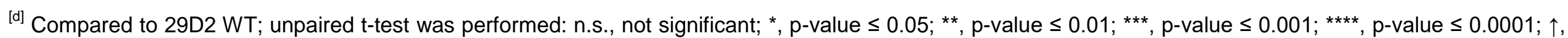
more than 29D2 WT; $\downarrow$, less than 29D2 WT

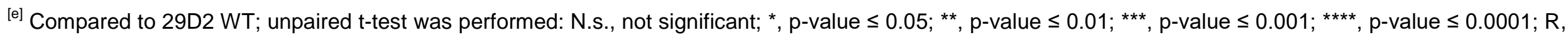
resistant; S, susceptible 
1 Table 3. Minimal inhibitory concentration (MIC) of ampicillin, tetracycline and

2 imipenem determined from ATCC 17978 wildtype/mutants and 29D2

3 wildtype/mutants. A dark grey background indicates that MIC values of mutant

4 strains are significantly elevated compared to the wildtype while a light grey

5 background indicates increased susceptibility

\begin{tabular}{|c|c|c|c|c|c|c|c|}
\hline \multirow{2}{*}{ Locus tag } & \multirow{2}{*}{ Gene name } & \multicolumn{2}{|c|}{ Ampicillin $^{a}$} & \multicolumn{2}{|c|}{ Imipenem $^{\mathrm{a}}$} & \multicolumn{2}{|c|}{ Tetracycline $^{a}$} \\
\hline & & ATCC 17978 & 29D2 & ATCC 17978 & 29D2 & ATCC 17978 & 29D2 \\
\hline Wildtype & & 25.3 & 36.5 & 0.23 & 0.25 & 2.1 & 3.25 \\
\hline A1S_2187 & purH & 32 & 18.6 & 0.23 & 0.21 & 1.6 & 1.5 \\
\hline A1S_2251 & purF & 48 & 16.0 & 0.25 & 0.16 & 3.0 & 2.3 \\
\hline A1S_2605 & purM & 53.3 & 17.3 & 0.21 & 0.18 & 1.0 & 2.3 \\
\hline A1S_2964 & purE & 53.3 & 10.6 & 0.13 & 0.21 & 1.5 & 2.0 \\
\hline A1S_1566 & & 96 & 18.6 & 0.23 & 0.23 & 1.8 & 0.9 \\
\hline A1S_2687 & $\operatorname{car} B$ & 32 & 3.0 & 0.10 & 0.03 & 0.9 & 2.0 \\
\hline A1S_0414 & & 106.6 & 32.0 & 0.23 & 0.25 & 1.6 & 2.0 \\
\hline A1S_1624 & & 32 & - & 0.125 & - & 2.1 & - \\
\hline A1S_0447 & rpmG & 29.3 & - & 0.16 & - & 1.0 & - \\
\hline A1S_0778 & metG & 32 & - & 0.23 & - & 0.46 & - \\
\hline A1S_0530 & & 24 & - & 0.19 & - & 2.0 & - \\
\hline A1S_3366 & gshA & 85.3 & 26.6 & 0.29 & 0.23 & 1.6 & 2.0 \\
\hline A1S 1970 & & 64 & 32.0 & 0.16 & 0.25 & 2.5 & 1.8 \\
\hline
\end{tabular}




\begin{tabular}{|c|c|c|c|c|c|c|c|}
\hline A1S_2840 & ompA & 29.3 & 13.3 & 0.46 & 0.13 & 1.5 & 3.0 \\
\hline A1S_3297 & & 58.6 & - & 0.33 & - & 2.0 & - \\
\hline A1S_2453 & $d d c$ & 32 & 5.0 & 0.46 & 0.14 & 0.38 & 4.6 \\
\hline A1S_2454 & dat & 26.6 & 5.3 & 0.25 & 0.23 & 0.29 & 6.0 \\
\hline A1S_0113 & & 42.6 & - & 0.25 & - & 2.0 & - \\
\hline A1S_0116 & & 85.3 & 29.3 & 0.21 & 0.33 & 2.6 & 1.5 \\
\hline A1S_0222 & aamA & 18.6 & 42.6 & 0.125 & 0.38 & 0.9 & 2.6 \\
\hline A1S_0065 & galE & 53.3 & 13.3 & 0.23 & 0.18 & 3.0 & 2.0 \\
\hline A1S_0806 & & 53.3 & 13.3 & 0.38 & 0.023 & 2.0 & 1.6 \\
\hline A1S_1055 & & 26.6 & 21.3 & 0.29 & 0.14 & 1.3 & 1.6 \\
\hline A1S_2182 & gidA & 37.3 & 24.0 & 0.19 & 0.25 & 3.0 & 4.0 \\
\hline A1S_2334 & $\operatorname{sahH}$ & 74.6 & - & 0.18 & - & 1.8 & - \\
\hline A1S_2587 & ruvA & 53.3 & - & 0.19 & - & 1.0 & - \\
\hline A1S_2610 & comEC & 29.3 & 5.3 & 0.23 & 0.10 & 1.6 & 0.6 \\
\hline A1S_2761 & prpF & 42.6 & 14.6 & 0.25 & 0.16 & 0.8 & 0.5 \\
\hline A1S_3026 & & 106.6 & 64.0 & 0.42 & 0.46 & 2.6 & 1.5 \\
\hline A1S_3129 & astB & 74.6 & - & 0.23 & - & 1.1 & - \\
\hline
\end{tabular}

6 averaged MIC values in [ $\left.{ }^{\mathrm{a}} \mathrm{g} / \mathrm{mL}\right]$ determined from three independent experiments. '-' indicates 'not

7 tested' 


\begin{tabular}{l|l|l}
\hline Locus tag in ATCC 17978 & $\begin{array}{c}\text { Annotation/ } \\
\text { gene name }\end{array}$ & Known relationship in other bacteria \\
\hline
\end{tabular}

Purine/pyrimidine/folate biosynthesis

\begin{tabular}{|c|c|c|}
\hline A1S_2187 & purH & $\begin{array}{l}\text { biofilm formation in Bacillus cereus [48]; } \\
\text { virulence in B. anthracis [54]; } \mathrm{K}^{+} \text {-dependent } \\
\text { colony spreading in Bacillus subtilis [45]; } \\
\text { Enterococcus faecium growth in human } \\
\text { serum [49]; defects in rifampicin persistence } \\
\text { in S. aureus [56] }\end{array}$ \\
\hline A1S_2251 & purF & $\begin{array}{l}\text { virulence in A. baumannii [52]; } \mathrm{K}^{+} \text {- } \\
\text { dependent colony spreading in Bacillus } \\
\text { subtilis [45]; virulence in Pasteurella } \\
\text { multocida [55]; virulence of Burkholderia } \\
\text { cenocepacia in G. mellonella, C. elegans, D. } \\
\text { melanogaster infection [51]; defects in } \\
\text { rifampicin persistence in S. aureus [56] }\end{array}$ \\
\hline A1S_2605 & purM & $\begin{array}{l}\text { virulence in A. baumannii [52]; } \mathrm{K}^{+} \text {- } \\
\text { dependent colony spreading in Bacillus } \\
\text { subtilis [45]; defects in rifampicin persistence } \\
\text { in S. aureus [56]; pellicles in A. baumannii } \\
\text { ATCC } 17978 \text { [43] }\end{array}$ \\
\hline A1S_2964 & purE & $\begin{array}{l}\text { virulence in S. pneumoniae [53] and A. } \\
\text { baumannii [52]; motility (purK) in A. } \\
\text { nosocomialis [26]; pellicles in A. baumannii } \\
\text { ATCC } 17978 \text { (PurB, PurD) [43] }\end{array}$ \\
\hline A1S_1566 & & - \\
\hline A1S_2687 & carB & $\begin{array}{l}\text { swimming motility and biofilm formation in } \\
\text { Xanthomonas citri subsp. citri [61]; virulence } \\
\text { in A. baumannii [52]; growth of E. coli in } \\
\text { human serum [50] }\end{array}$ \\
\hline
\end{tabular}




\begin{tabular}{|c|c|}
\hline A1S_0414 & - \\
\hline A1S_1624 & $\begin{array}{c}\text { motility in E. coli [66]; pellicles in } \\
\text { A. baumannii ATCC } 17978 \text { [43]; biofilm } \\
\text { formation in Pseudomonas fluorescens [70]; } \\
\text { virulence in Salmonella enterica [67]; } \\
\text { antibiotic susceptibility in E. coli, } \\
\text { A. baumannii and P. aeruginosa [68]; } \\
\text { antibiotic tolerance [69] }\end{array}$ \\
\hline
\end{tabular}

RNA modification/regulation

\begin{tabular}{|c|c|c|}
\hline A1S_0447 & rpmG & mitomycin $C$ resistance in $E$. coli [82] \\
\hline A1S_0778 & metG & $\begin{array}{c}\text { virulence in A. baumannii [52]; antibiotic } \\
\text { tolerance in Burkholderia thailandensis [79] } \\
\text { and E. coli }[80,81] \text {; pellicles in A. baumannii } \\
\text { ATCC } 17978 \text { [43] }\end{array}$ \\
\hline A1S_2182 & gidA & $\begin{array}{l}\text { review gid operon, virulence, motility, biofilm } \\
\text { formation, antibiotic resistance, bacterial } \\
\text { growth [75]; swarming motility, pellicle } \\
\text { biofilm in Bacillus cereus [47]; swarming } \\
\text { motility in Serratia species SCBI [73] and } \\
\text { Pseudomonas syringae [74]; proteomic } \\
\text { analysis in A. baumannii [76]; biofilm } \\
\text { formation in Pseudomonas fluorescens [77] } \\
\text { and Streptococcus mutans [78] }\end{array}$ \\
\hline
\end{tabular}

Oxidative stress

A1S_0530

A1S 3366
gshA virulence in Salmonella Typhimurium [144];

thioredoxin involved in $A$. baumannii

virulence [145]; general oxidative stress

response genes involved in pellicles in $A$.

baumannii ATCC 17978 [43]

swarming and swimming motility in $P$. aeruginosa, decrease in biofilm formation [85]; swimming and twitching motility in $P$. 


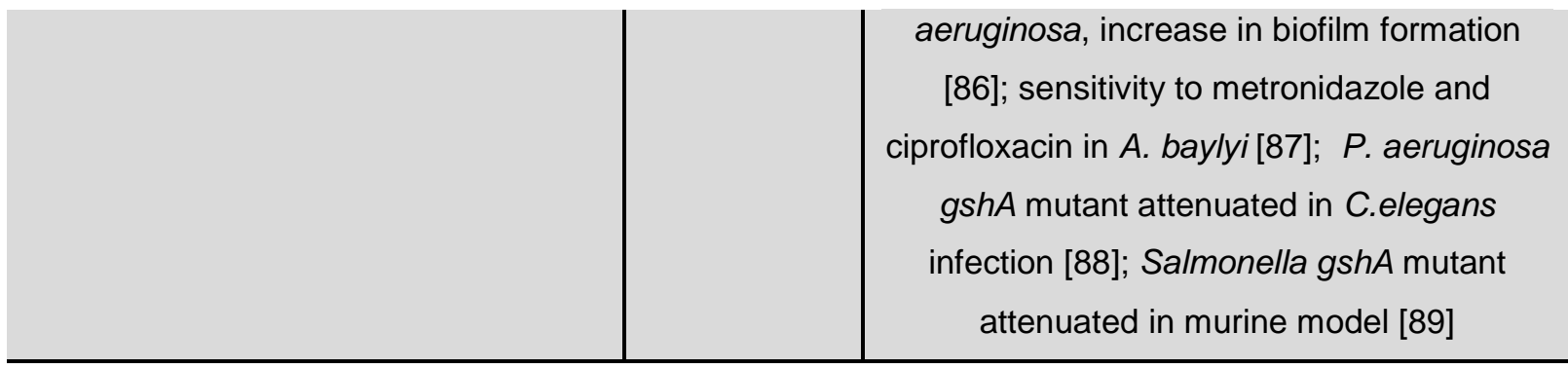

Outer membrane proteins

\begin{tabular}{|c|c|c|}
\hline A1S_1970 & & - \\
\hline A1S_2840 & ompA & $\begin{array}{c}\text { A. nosocomialis surface-associated motility } \\
\text { [26]; biofilm formation [94-96]; bacterial } \\
\text { pathogenicity - Review [97]; virulence } \\
\text { [11,103,104]; A. baumannii virulence in C. } \\
\text { elegans [98]; K. pneumoniae virulence in G. } \\
\text { mellonella [99]; antibiotic resistance [105]; } \\
\text { pellicles in A. baumannii ATCC } 17978 \text { [43] }\end{array}$ \\
\hline A1S_3297 & & $\begin{array}{l}\text { general outer membrane proteins involved in } \\
\text { pellicles in A. baumannii ATCC } 17978 \text { [43] }\end{array}$ \\
\hline
\end{tabular}

1,3-diaminopropane biosynthesis

A1S 2453

A1S_2454

Lipopeptide synthesis/ export

A1S_0113

A1S 0116 ddc surface-associated motility and virulence in

A. baumannii [33]

\begin{tabular}{l|l} 
A1S_0113 & $\begin{array}{c}\text { temperature dependent antibiotic resistance } \\
\text { and surface motility in A. baumannii [146]; } \\
\text { surface-associated motility in A. baumannii } \\
\text { and } A . \text { nosocomialis [26,38]; pellicle biofilm } \\
\text { formation in A. baumannii [38]; biofilm } \\
\text { formation on abiotic surfaces in } A . \\
\text { baumannii [107,106]; pellicles in } A . \\
\text { baumannii ATCC 17978 [43]; imipenem- } \\
\text { selected A. baumannii [108] }\end{array}$ \\
\hline
\end{tabular}

DNA modification/repair/uptake

A1S_0222

aamA

protein purification of $A$. baumannii AamA

[110]; review of phenotypes caused by dam 


\begin{tabular}{|c|c|c|}
\hline & & mutants or dam overexpression [115] \\
\hline A1S_2334 & $\operatorname{sahH}$ & biofilm formation [147] \\
\hline A1S_2587 & ruvA & - \\
\hline A1S_2610 & comEC & $\begin{array}{l}\text { surface motility, twitching motility, virulence } \\
\text { in } A \text {. baumannii [16]; twitching motility in } \\
\text { Thermus thermophiles [116]; virulence and } \\
\text { growth in L. monocytogenes [117]; biofilm } \\
\text { formation [118] }\end{array}$ \\
\hline
\end{tabular}

\section{Other}

\begin{tabular}{|c|c|c|}
\hline A1S_0065 & gale & $\begin{array}{l}\text { virulence in A. baumannii [52], Bacillus } \\
\text { anthracis [128], Streptococcus iniae [129], } \\
\text { Leptosphaeria maculans [130]; biofilm } \\
\text { formation in Sinorhizobium meliloti [121], } \\
\text { Vibrio cholerae [122], Bacillus subtilis [123], } \\
\text { Thermus thermophiles [124], Haemophilus } \\
\text { parasuis [125], Porphyromonas gingivalis } \\
\text { [126], A. baumannii [76]; antibiotic } \\
\text { resistance/susceptibility in Porphyromonas } \\
\text { gingivalis [126], Salmonella typhimurium } \\
\text { [131], Salmonella typhi [132]; A. baumannii } \\
\text { biofilm (galU, galM) [127]; surface motility of } \\
\text { A. nosocomialis (rmIB) [26] }\end{array}$ \\
\hline A1S_0806 & & $\begin{array}{l}\text { survival, growth and virulence of } \\
\text { mycobacteria bioA }[137,148-150]\end{array}$ \\
\hline A1S_1055 & & $\begin{array}{l}\text { Iytic transglycosylase (A1S_3027) in A. } \\
\text { nosocomialis motility [26] }\end{array}$ \\
\hline A1S_2761 & $p r p F$ & pellicles in A. baumannii ATCC 17978 [43] \\
\hline A1S_3026 & & $\begin{array}{c}\text { reviews of T2 Family Ribonucleases } \\
\text { [151,152]; abiotic surface colonization in } A \text {. } \\
\text { baumannii [34]; colistin resistance in } A \text {. } \\
\text { baumannii [138] }\end{array}$ \\
\hline A1S_3129 & astB & $\begin{array}{l}\text { virulence in } A \text {. baumannii [52]; pellicles in } A \text {. } \\
\text { baumannii ATCC } 17978 \text { [43] }\end{array}$ \\
\hline
\end{tabular}


bioRxiv preprint doi: https://doi.org/10.1101/2020.03.18.992537; this version posted March 18, 2020. The copyright holder for this preprint (which was not certified by peer review) is the author/funder, who has granted bioRxiv a license to display the preprint in perpetuity. It is made available under aCC-BY 4.0 International license. 